Manuscript to Phytochemistry

\title{
Glucosinolate turnover in Brassicales species to an oxazolidin-2-one, formed via the 2-thione and without formation of thioamide
}

Niels Agerbirk ${ }^{1}$, Annemarie Matthes ${ }^{1}$, Pernille $\varnothing$. Erthmann ${ }^{1}$, Luisa Ugolini ${ }^{2}$, Susanna Cinti ${ }^{2}$, Eleni Lazaridi ${ }^{1}$, Jean-Marc Nuzillard ${ }^{4}$, Caroline Müller ${ }^{3}$, Søren Bak ${ }^{1}$, Patrick Rollin ${ }^{5}$, Luca Lazzeri

${ }^{1}$ Copenhagen Plant Science Center and Department of Plant and Environmental Sciences, University of Copenhagen, Rolighedsvej 40, 1871 Frederiksberg C, Denmark.

${ }^{2}$ Council for Agricultural Research and Economics, Research Centre for Cereal and Industrial Crops, Via di Corticella 133, 40128, Bologna, Italy

${ }^{3}$ Department of Chemical Ecology, Bielefeld University, Universitätsstr. 25, 33615 Bielefeld, Germany

${ }^{4}$ Université de Reims Champagne-Ardenne and CNRS, Institut de Chimie Moléculaire de Reims, UMR 7312, SFR CAP'SANTE, F-51687 Reims, France.

${ }^{5}$ Université d'Orléans and CNRS, ICOA, UMR 7311, BP 6759, F-45067 Orléans, France 


\begin{abstract}
Glucosinolates are found in plants of the order Brassicales and hydrolyzed to different breakdown products, particularly after tissue damage. In Barbarea vulgaris (Brassicaceae), the dominant glucosinolate is glucobarbarin, (S)-2-hydroxyphenethylglucosinolate. Resedine (5-phenyl-1,3-oxazolidin-2-one) was detected after glucobarbarin hydrolysis in crushed $B$. vulgaris leaves and siliques, but not in intact parts. The abundance increased for several hours after completion of hydrolysis. The corresponding oxazolidine2-thione (OAT), known as barbarin, was also formed, and appeared to be the precursor of resedine. Addition of each of two non-endogenous OATs, $(S)$-5-ethyl-5-methylOAT and $(R)$-5-vinylOAT ( $R$-goitrin), to a leaf homogenate resulted in formation of the corresponding oxazolidin-2-ones (OAOs), confirming the metabolic connection of OAT to OAO. Formation of OAOs was inhibited by prior brief heating of the homogenate, suggesting enzyme involvement. We suggest the conversion of OATs to OAOs to be catalyzed by an enzyme ("oxazolidinethionase") responsible for turnover of OAT formed in intact plants. Resedine had been reported as an alkaloid from another species, Reseda luteola (Resedaceae), naturally containing the glucosinolate glucobarbarin. However, resedine was not detected in intact $R$. luteola plants, but formed after tissue damage. The formation of resedine in two families suggests a broad distribution of putative OATases in the Brassicales. Several candidate genes for glucosinolate turnover in intact $B$. vulgaris plants are reported. We suggest that biotechnological conversion of OATs to OAOs might improve the nutritional value of Brassicales protein. Formation of the nitrile from glucobarbarin was observed in vitro, while a previously suggested thioamide (synonym thionamide) was not confirmed. HPLC-MS/MS methods for detection of these glucobarbarin products are described.
\end{abstract}

Key-words: Glucosinolate hydrolysis; turn-over; 1,3-oxazolidine-2-thione; 1,3-oxazolidin-2-one; nitrile, thioamide; Barbarea; Reseda; Nasturtium 


\section{Introduction}

1,3-Oxazolidin-2-ones (OAOs) are important as structural elements in modern antibiotics, the first of which was linezolid targeting bacterial protein synthesis (Diekema and Jones, 2001). Likewise, several OAOs are important as auxiliaries in chiral synthesis (Gnas and Glorius, 2006). They are also known as Evans auxiliaries and used for controlling aldol reactions (Evans et al., 1981). In this report, we argue that this class of compounds is also formed from enzymatic turnover of glucosinolates, a group of natural $S$ glucosides (Halkier and Gershenzon, 2006; Agerbirk and Olsen, 2012).

It is well known that a related group of heterocycles, the substituted 1,3-oxazolidine-2-thiones (OATs), are found in many glucosinolate-containing plants. Both OAOs and OATs are named as deriving from the parent heterocycle azzolidine (Figure 1), explaining the middle ' $A$ ' in our abbreviations. Penicillin contains a third pattern, a thiazolidine ring (Figure 1). Natural diversity of heterocyclic secondary metabolites was studied by several researchers, inspired by the remarkable progress in penicillin chemistry in the first half of the $20^{\text {th }}$ century. Two reports independently showed that OATs were formed via cyclisation of $\beta$-hydroxyalkyl isothiocyanates produced from $\beta$-hydroxyalkyl glucosinolates (Greer, 1956; Kjær et al., 1956). For example, $(R)$-5-phenyIOAT ( $R$-barbarin, 2 ) is formed via a never isolated $\beta$-hydroxy isothiocyanate derived from (S)-2hydroxy-2-phenylethylglucosinolate (glucobarbarin, 1) (Figure 2) (Kjær and Gmelin, 1957; Agerbirk and Olsen, 2015). The enantiomer, $S$-barbarin, is formed from the epimeric glucosinolate epiglucobarbarin (Gmelin et al., 1970). Benzyl-activating substitution of glucobarbarins changes the type of hydrolysis product to a thiazolidin-2-one (TAO), an additional heterocycle in this plant group (Figure 1) (Agerbirk and Olsen, 2015). A thermally induced rearrangement of 5-phenyIOAT to 5-phenyITAO is also well established (Lutfullin et al., 1976; Radulovic et al., 2017). From an epithionitrile, further heterocyclic rings were also recently reported a downstream products of glucosinolate hydrolysis, including a thiophene (Hanschen et al., 2018).

Glucosinolates are found throughout the order Brassicales (Blaževic et al., 2015), with around 144 documented structures reported by 2016 (Agerbirk and Olsen, 2012; Matich et al., 2012; Montaut et al., 2015; Agerbirk et al., 2015; Pedras et al., 2016; Olsen et al., 2016; Pfalz et al., 2016) and a further reported 3-5 structures from 2017, including 5-phenylpentylglucosinolate (Dekic et al., 2017) and 4-hydroxy-3,5dimethoxybenzylglucosinolate (Pagnotta et al., 2017). Although some structural features seem to be restricted to smaller taxonomic groups, there is also a great redundancy in structures found in widely separated taxonomic groups (Blaževic et al., 2015; Olsen et al., 2016). A widespread structural feature is $\beta$ hydroxylation of the glucosinolate side-chain catalyzed by GS-OH enzymes (Hansen et al., 2008; Liu et al., 2016, Olsen et al., 2016; Byrne et al., 2017). Indeed, the $\beta$-hydroxylated glucosinolate glucobarbarin (1) is found in Resedaceae (e.g. Reseda luteola L.) (Kjær and Gmelin, 1958; Radulovic et al., 2017) as well as in Brassicaceae (e.g. most or all Barbarea spp. and some accessions of Nasturtium officinale) (Kjær and Gmelin, 1957; Agerbirk and Olsen, 2011; Agerbirk et al., 2014).

From $R$. luteola, two alkaloids were described in an early report (Lutfullin et al., 1976). One was a substituted OAT, while the other was a substituted OAO, a further heterocyclic ring in the order Brassicales (Figure 1). The OAT was named resedinine, but was identical to barbarin. Hence the older name has priority, and the name resedinine should be abandoned. The OAO was named resedine and identified as 5phenyIOAO (Figure 2). Relations to plant biochemistry or glucosinolate turnover were not investigated.

Of the many known OATs in the Brassicales, one has received a particular attention: $(S)$-5-vinylOAT ((S)goitrin) formed from the glucosinolate progoitrin $((R)$-2-hydroxybut-3-enylglucosinolate) in oilseed rape (Greer, 1956). Despite decades of breeding efforts to lower levels of progoitrin and goitrin (Nour-Eldin, 
2017), these metabolites remain a limiting factor for the use of protein from these plants in fodder. Some of the antinutritional effects of goitrin and other OATs seem to be related to disturbance of iodine metabolism and catalysis of nitrite reactions in mammals (reviewed in Agerbirk et al., 2014; Felker et al., 2016). A recent investigation has broadened the range of known effects of OATs (Radulovic et al., 2017).

Glucosinolate hydrolysis is catalyzed by isoenzymes of thioglucoside glucohydrolase (E.C. 3.2.1.147) commonly known as myrosinases. Myrosinase-catalyzed turnover of glucosinolates mainly happens after tissue disruption, because enzyme and substrate are spatially separated in intact plants (Wittstock et al., 2017). However, other enzymes responsible for turnover of glucosinolates in intact plants have been identified in recent years (reviewed by Pastorczyk and Bednarek, 2016; Wittstock et al., 2017). Some unexpected, non-conventional degradation products have been reported, suggesting a varied and complex metabolism of glucosinolates in intact plants (Montaut and Bleeker, 2010; Agerbirk and Olsen, 2012; Pedras et al., 2016; Klein and Sattely, 2017). To our knowledge, nothing is known of metabolism or detoxification of OATs in intact plants.

From non-enzymatic breakdown of glucobarbarin and progoitrin catalyzed by high concentrations of ferrous salts, thioamides were reported in high yields, on the base of limited analytical evidence (Austin et al., 1968a and b). A later report provided circumstantial evidence - including UV-spectral evidence only - for the formation of low levels of the thioamide from epiglucobarbarin at similar high ferrous ion conditions, and suggested that this thioamide (syn. thionamide) could also be formed during enzymatic hydrolysis with lower concentrations of ferrous salts (Bellostas et al. 2008).

In order to better understand ecological functions of glucobarbarin, we investigated its breakdown products. Our initial objective was to isolate the biochemical hydrolysis products from glucobarbarin, expected to be barbarin, 3-hydroxy-3-phenylpropanenitrile (4) and possibly the related thioamide (hypothetic " 5 "). However, an unexpected product with the same nominal mass as a potential thioamide fragment appeared, so an additional goal was to identify this OAO product and test for an enzymatic formation from the corresponding OAT. We here report lack of formation of a thioamide, scarce formation of the nitrile, and unexpected formation of OAOs via OATs effected by a heat sensitive factor in glucobarbarin-containing plants. The formation of the OAO resedine is characterized and the connection to glucosinolate turnover investigated.

\section{Results and discussion}

\subsection{Identification of the nitrile from glucobarbarin hydrolysis}

One glucobarbarin product, barbarin (2), was already at hand, and ion trap HPLC-MS was optimized for optimal detection in the relevant mass range for glucobarbarin products (Section 3.6). In order to obtain the nitrile from glucobarbarin, the isolated glucosinolate was subjected to myrosinase-catalyzed hydrolysis in a well-defined in vitro system at $\mathrm{pH} 5$ in the presence and absence of $2.5 \mathrm{mM}$ of a ferrous salt, $\mathrm{FeCl}_{2}$. As expected, both barbarin and a product with mass spectrum matching the expected nitrile (4) were formed in both conditions, with barbarin dominating without added $\mathrm{FeCl}_{2}$ and the nitrile $\mathbf{4}$ dominating with added $\mathrm{FeCl}_{2}$ (Figure 3).

A previously suggested thioamide (hypothetic " 5 ") was searched for but not confirmed (Figure 3 ). Resedine (3), discussed below, was not detected either. The ion trap MS of $\mathbf{4}$ was dominated by the sodium adduct and a proton adduct after loss of water, while the proton adduct itself was minor (Figure 4a). By comparison with two related model compounds, we could confirm that such loss of water was predictable for $\mathbf{4}$ because of the $\beta$-position of the hydroxyl group. The phenolic isomer $\mathbf{6}$ lost water to a much lower 
extent in ion trap MS (Figure 4b), while association of both hydroxyl substitutions (7) led to complete loss of water from the proton adduct due to the activating effect of the $p$-hydroxy group (Figure 4c). High resolution MS confirmed the identity of 4 (found: $130.0649\left[\mathrm{M}-\mathrm{H}_{2} \mathrm{O}+\mathrm{H}\right]^{+}$, calculated for $\mathrm{C}_{9} \mathrm{H}_{8} \mathrm{~N}^{+}:$130.0651). As 1 was precursor and ferrous salts are well known to stimulate nitrile formation from glucosinolate hydrolysis, the structure of product $\mathbf{4}$ was ascertained as $\mathbf{4}$ (3-hydroxy-3-phenylpropanenitrile).

\subsection{Amide but no thioamide detected from in vitro, non-enzymatic glucobarbarin breakdown with a ferrous salt}

We were intrigued by the historical report of 3-hydroxy-3-phenylpropanethioamide (hypothetic " 5 ") from glucobarbarin at high ferrous salt concentrations (Austin et al., 1968a) and the tentatively suggestion that it could be a more general metabolite (Bellostas et al. 2008). In an attempt to obtain a reference, the reported procedure (Austin et al., 1968a) was repeated with slight modifications (Section 3.5). Extensive glucobarbarin degradation (92\%) after incubation with $150 \mathrm{mM}$ ferrous ammonium sulfate was confirmed by HPLC-analysis (Figure 5A). However, product analysis by HPLC-DAD did not reveal any peak matching the suggested thioamide with $\lambda_{\max }$ at $267 \mathrm{~nm}$ (Austin et al., 1968a). In an ethyl acetate extract (Figure 5B), the two major products absorbing at $210 \mathrm{~nm}$ were isolated by HPLC and identified as 3-hydroxy-3phenylpropanamide (8, tentative) and the nitrile $\mathbf{4}$ by ion trap HPLC-MS/MS and high resolution HPLC-MS. Formed along with a nitrile, the amide $\mathbf{8}$ was considered a reasonable structure, as it can be likened to hydrated nitrile. In the ion trap with eluents doped with $\mathrm{NaCl}$, the sodium adduct was dominant (Figure $5 \mathrm{C}$ ). The suggested identity was supported by high resolution MS (found: $166.0866[\mathrm{M}+\mathrm{H}]^{+}$, calculated for 8, $\mathrm{C}_{9} \mathrm{H}_{12} \mathrm{O}_{2} \mathrm{~N}^{+}:$166.0863]). Fragmentation of the sodium adduct in ion trap MS supported the identity, as the major loss of 59 amu matched loss of acetamide, leaving an ion with the composition as a sodium adduct of benzaldehyde $(\mathrm{m} / \mathrm{z} 129)$. The hydrogen adduct detected in high resolution MS fragmented differently, with major loss of $60 \mathrm{amu}$ (acetic acid) leaving a fragment matching the composition of phenylmethaniminium ion (found: 106.0653 [M-acetic acid+H] $]^{+}$, calculated for $\mathrm{C}_{7} \mathrm{H}_{8} \mathrm{~N}^{+}:$106.0651). We find acid-catalyzed rearrangement with loss of acetic acid in agreement with the proposed structure, $\mathbf{8}$. Searching the data files after ion trap HPLC-MS of the entire ethyl acetate extract did not reveal any signs of the presence of the suggested thioamide " 5 ". Specifically, we searched for expected $m / z$ values of hypothetic " 5 ": $182[\mathrm{M}+\mathrm{H}]^{+}$ or $204[\mathrm{M}+\mathrm{Na}]^{+}$or $164\left[\mathrm{M}-\mathrm{H}_{2} \mathrm{O}+\mathrm{H}\right]^{+}$. This expected MS was based on experience with related metabolites 4 , 6, 7 and 8 (Figure 4, Figure 5).

Observation of an amide (8) but no thioamide (" 5 ") could not be explained by contamination with the reagents described later, catalyzing conversion of the thiocarbonyl functional group in OATs to the carbonyl functional group in OAOs. This could be firmly concluded for logistic reasons (Section 3.5).

\subsection{Resedine formed after autolysis in Reseda, Barbarea and Nasturtium}

The spontaneous hydrolysis of glucosinolates in crushed Brassicales plant material is termed autolysis. As the profile of non-OAT glucobarbarin hydrolysis products in green parts of $B$. vulgaris was completely unknown, we first investigated the autolysis of $B$. vulgaris foliage (upper leaves of flowering plants of the 'G-type' of this species, which is rich in glucobarbarin) (Agerbirk et al., 2015). As expected, the OAT barbarin (2) was a major autolysis product, while the nitrile (4) was not detected or at trace levels. Despite the complex nature of B. vulgaris metabolite extracts (Dalby-Brown et al., 2010; Khakimov et al., 2016), the chromatograms contained only few major peaks (Figure 6), probably because the MS detector was targeted at low $\mathrm{m} / \mathrm{z}$ values (target $\mathrm{m} / \mathrm{z} 180$ ), in practice resulting in a quasi-normal distribution of detected $\mathrm{m} / \mathrm{z}$ values centered around the target and leaving $\mathrm{m} / \mathrm{z}$ values above ca. 300 undetected (Section 3.6). With 
these detector settings, we noticed a medium intensity peak with MS2 similar to that of barbarin. As explained below, the metabolite in this peak was shown to be resedine (3).

Resedine formation in $B$. vulgaris was detected in plant parts sampled from the investigated $2^{\text {nd }}$ year plants over a period of three months, in leaves as well as in siliques. Resedine formation was also observed in dry seeds homogenized in water and in seedlings (Table 1). The peak was much smaller than the barbarin peak soon after complete glucosinolate hydrolysis (at $0.5 \mathrm{~h}$ after crushing the plant part in a mortar), but increased in intensity over time (Figure 6A). In extracts of intact foliage, resedine was not detected, while barbarin was detected at much reduced levels (around $5 \%$ of levels after intended complete autolysis), as expected for an artifact from 'partial autolysis during handling and extraction'.

The ion trap mass spectrum of barbarin is characteristic, with major losses of CSO and $\mathrm{H}_{2} \mathrm{~S}$ (Figure $6 \mathrm{C}$ ). The metabolite proving to be resedine showed the same fragments as barbarin, whereas the molecular ions $[\mathrm{M}+\mathrm{H}]^{+}$and $[\mathrm{M}+\mathrm{Na}]^{+}$had $\mathrm{m} / \mathrm{z}$ values 16 amu lower than those of barbarin (Figure 6D). It seemed obvious that this metabolite was related to barbarin, but with the sulfur replaced by oxygen. Indeed, the UV band from $C=S$ at $242 \mathrm{~nm}$ in barbarin was missing (Supplementary Figure 1). For NMR analysis, resedine was isolated by HPLC from foliage autolyzed for $24 \mathrm{~h}$ (Supplementary Figure 2). The proton NMR spectrum, with a complex cluster of resonances from the phenyl group in the 7.37-7.44 ppm interval, and three coupled signals of $\mathrm{H} 5$ (5.64 ppm, apparent t), $\mathrm{H} 4 \mathrm{a}$ (3.98 ppm, apparent dt) and H4b (3.54, ddd) was in excellent agreement with literature spectra (Sheng et al., 2017; Lutfullin et al., 1976). First order analysis was not possible, but PERCH analysis confirmed the interpretation and provided accurate chemical shifts and coupling constant values (Supplementary Figure 3). High resolution MS confirmed also the interpretation above of MS2 fragmentation, with major losses of $\mathrm{H}_{2} \mathrm{O}$ and $\mathrm{CO}_{2}$ from the proton adduct. The ion trap HPLCMS of resedine peak also agreed with a synthetic specimen prepared from $\mathbf{2}$ at oxidizing conditions, using $\mathrm{H}_{2} \mathrm{O}_{2}$ in a procedure simplified and scaled down from the literature (Section 3.12).

Literature search revealed that $\mathbf{3}$ was a known natural product reported as an alkaloid from R. luteola and hence named resedine (Lutfullin et al., 1976). Extraction and analysis of that plant species showed that resedine was not detectable in intact foliage, but was a medium-abundance peak after autolysis (Figure 6B, Table 1). We also searched old data files (Agerbirk et al., 2014) from analysis of autolysis products of glucobarbarin in watercress, Nasturtium officinale, and observed a peak with the four characteristic ions of resedine, reasonable $t_{R}$ compared to barbarin, and lacking in extracts without autolysis (Supplementary Figure 4). We concluded that resedine is formed after autolysis, possibly as a downstream glucobarbarin product (Figure $6 \mathrm{~A}+\mathrm{B}$ ), in at least three Brassicales species, but is not a major metabolite in intact tissue of any of the species.

\subsection{Only traces of nitrile and no thioamide as autolysis products}

The nitrile, detected with certainty from in vitro breakdown of glucobarbarin by myrosinase as well as with a ferrous salt, was not detected with certainty in any of our autolysis experiments. The low amounts reported in Table 1 are maximum estimates calculated from minor or trace peaks, of which none were confirmed by MS2. However, the spectrum of putative $\mathbf{4}$ from seedlings revealed good resemblance with the reference spectrum. As some plants convert nitriles into amides enzymatically (Agerbirk et al., 2007), we also searched the autolysis extracts for the corresponding amide 8. A trace was detected in all analyzed samples after autolysis, but an equally abundant trace was also detected in many samples before autolysis and in a species (Reseda odorata L.) not containing glucobarbarin. The identity of the putative $\mathbf{8}$ could not be ascertained by MS2 in any sample due to very low levels. Hence, we concluded that the amide $\mathbf{8}$, if present at all, was a low level constituent not derived from glucobarbarin turn-over. 
Inspired by the in vitro stimulation of nitrile formation by a ferrous salt (Section 2.1.), an equivalent level of $\mathrm{FeSO}_{4}$ was added to a leaf before homogenization (Table 1). However, a slight possible increase of nitrile formation in one experiment was far less than in the in vitro experiment, suggesting that other binding sites competed for ferrous ion in the homogenate.

In systematic attempts to reproduce the historical report of a thioamide from glucobarbarin degradation, we searched a variety of chromatograms including autolysis samples with and without added ferrous salt for the expected $m / z$ values of hypothetic " 5 ". However, no candidate peak was found, except that the expected loss-of-water fragment mass $(\mathrm{m} / \mathrm{z} 164)$ matched resedine (3) discussed above. We also analyzed samples with HPLC-DAD and searched UV traces at $267 \mathrm{~nm}$ for peaks with the reported UV spectrum, with a maximum at $267 \mathrm{~nm}$ (Austin et al., 1968a), but found no candidate peaks. In general, HPLC-DAD chromatograms were complex, and $\mathbf{4}$ and to some extent $\mathbf{3}$ were disturbed by coeluting peaks (Supplementary Figure 2). No conclusive evidence for a thioamide (" 5 ") formed from glucobarbarin has ever been reported, despite two claimsbut these suggestions could not be confirmed despite systematic attempts (Section 2.2).

\subsection{Time course and heat sensitivity of formation of resedine in crushed tissue}

The time course of formation of resedine was further investigated, hoping that it would shed light on the mechanism of formation during autolysis. When varying the autolysis time for leaves and siliques, a quasilinear formation of resedine was observed over $3 \mathrm{~h}$ or more, suggesting that any needed additional reactant (other than barbarin) was continuously available in homogenized tissue (Figure 7A). These experiments were carried out with individual samples of leaves or siliques, and without buffer addition. As the individual samples could vary in initial glucobarbarin concentration, the appearance of resedine could only be defined in relative terms. From the long quasi-linear phase in the undiluted homogenates, we anticipate that any co-reactant would be a simple, abundant molecule like $\mathrm{H}_{2} \mathrm{O}$ or $\mathrm{O}_{2}$. A hydrolysis would be the simplest reaction class, but an oxidative reaction is also a possibility.

In order to test whether the catalyst responsible for resedine formation was heat sensitive, an additional experiment was carried out (Section 3.10). First, leaves were homogenized and incubated for $0.3 \mathrm{~h}$, allowing turnover of most of the glucobarbarin to barbarin. Then, the homogenate was divided in aliquots, which were suspended in water. In order to test for a heat sensitive catalyst without varying total incubation time, all suspended aliquots were incubated for an additional $25 \mathrm{~h}$ at room temperature, except for a brief ( $1 \mathrm{~min}$ ) boiling at either $0.3 \mathrm{~h}$ (i.e. immediately after suspension), $6.3 \mathrm{~h}$ or $24.3 \mathrm{~h}$ (Figure 7B). Hence, initial glucobarbarin levels were the same in all aliquots, and only the reaction time until boiling varied, not total incubation time or total heat exposure. While total amounts of barbarin and resedine increased slightly between $0.3 \mathrm{~h}$ and $6.3 \mathrm{~h}$, the absolute (and also relative) levels of resedine increased in both the $6.3 \mathrm{~h}$ and $24.3 \mathrm{~h}$ aliquots relative to the $0.3 \mathrm{~h}$ aliquot. In contrast to the experiments comprising autolysis without added buffer, a quasi-linear formation of resedine was not observed. The slower formation after buffer-addition suggested the reaction rate to be very sensitive to dilution of enzyme and/or substrate. As the time until boiling was the only factor varied in the experiment, we concluded that resedine was formed by a heat sensitive catalyst, most likely an enzyme. From a structural argument, barbarin was a likely precursor. In the following, we use the provisional name oxazolidinethionase (OATase) for the hypothesized enzyme. "Thionase" would be a simpler trivial name for an enzyme converting a thiocarbonyl to a carbonyl, but this name was abandoned because it has already been used historically for another enzyme, cystathionine beta synthase, E.C. 4.2.1.22, that catalyzes an apparently unrelated reaction. 
It is well established that OATs are unstable at very high temperature, as found in GC instruments (Lutfullin et al., 1976; Radulovic et al., 2017). Rearrangement to TAOs was reported at GC conditions. Hence, in the experimental design it was critical that all samples received the same heat treatment, but at different time after homogenization. Clearly, the factor determining the amount of resedine formed was not related to heat energy received, but to the reaction time allowed before heating was carried out. TAOs are detectable at our conditions (Agerbirk and Olsen, 2015), but were not observed, confirming that barbarin was stable at the moderate temperatures used here $\left(100^{\circ} \mathrm{C}\right.$ and below).

\subsection{Detection of heat-sensitive oxazolidinethionase acting on a spiked OAT in B. vulgaris homogenates}

As the enzyme was apparently sensitive to dilution or extraction (Fig. 7B), and we could neither avoid formation of glucobarbarin, nor its product barbarin, in $B$. vulgaris homogenates at room temperature, we could not conclude from the autolysis experiments whether those were precursors of resedine. Instead, we tested for a more general OAT converting enzyme (OATase): two additional OATs and an OAT precursor glucosinolate were spiked to $B$. vulgaris homogenates, which were analyzed for the corresponding OAOs after incubation. One of them was (S)-5-ethyl-5-methyIOAT (9), and conversion of this substrate to the corresponding OAO (10) was unequivocally demonstrated, as confirmed by the same $t_{R}$ and ion trap MS/MS as that of an authentic standard (Figure 8). This experiment, including relevant controls and testing two different OATs, is detailed below.

Addition of the OAT 9 did result in appreciable accumulation of the corresponding OAO 10 (Figure 9A+E), while this OAO was not seen in a control without the added OAT (Figure 9B+F). In contrast, a briefly heated homogenate essentially did not catalyze conversion of added $\mathbf{9}$ to $\mathbf{1 0}$ (Figure $9 C+G$ ). As a control for substrate impurities or general non-enzymatic formation of OAOs, 9 was incubated in parallel with a pH 5 buffer. A tiny OAO peak detected in the heated controls with homogenates was also observed in the heated buffer controls, apparently due to a minor contamination of the OAT substrate used for spiking (Figure 9D+H).

The other tested OAT was $(R)$-goitrin (11) with the systematic name $(R)$-5-vinylOAT. Addition of $(R)$-goitrin resulted in a minor but distinct peak of the corresponding OAO 12 (Supplementary Figure 5). The MS of the peak matched the MS of an authentic reference (Section 3.13) when background was taken into account (Supplementary Figure 5). The product peak (12) was confirmed to be essentially absent from a control of the substrate $\mathbf{1 1}$ incubated with pH 5 buffer, in accordance with the product peak being due to enzymatic conversion in the plant material. With this substrate (11) and product (12), peak intensities were about fivefold lower than seen for $\mathbf{9}$ and $\mathbf{1 0}$, despite the OATs $\mathbf{9}$ and $\mathbf{1 1}$ being added at similar concentration. The apparent lower sensitivity was a logical consequence of the lowered $M_{r}$, considering the quite narrow focusing of the ion trap MS detector. Indeed, UV detection (Supplementary Figure 6) confirmed that both OATs were present at high levels (calculated as ca. $10 \mathrm{mM}$ ), comparable to the endogenous level of barbarin. Thus, there was no evidence for different reaction velocities for the two tested OATs, $\mathbf{9}$ vs $\mathbf{1 1}$. As a a further control of sufficient access of the $(R)$-goitrin spike, addition of the glucosinolate precursor of $(R)$ goitrin, epiprogoitrin, resulted in formation of goitrin in situ (Supplementary Figure 6) and a minor peak of the corresponding $\mathrm{OAO}, 12$.

We concluded that a heat sensitive factor in $B$. vulgaris homogenates converts several OATs $(\mathbf{2}, \mathbf{9}$ and $\mathbf{1 1})$ into corresponding OAOs (3,10 and 12). As autolysis was going on in the homogenate before addition of the spike, and OATase activity was expected to slow down due to the experimental dilution, there was no reason to believe that formation of resedine would be significantly inhibited by one or more added OATs. 
Test for conversion of $(R)$-goitrin (11) was also relevant from an applied perspective, as $\mathbf{1 1}$ is formed from epiprogoitrin in the potential industrial crop Crambe abbysinica (Lazzeri et al, 1994). The (S)-goitrin enantiomer was not tested in this work. An OATase enzyme capable of removing the thione functionality of (S)-goitrin would seem to have potential in improving the nutritional value of rapeseed (Brassica napus) protein that suffer from (S)-goitrin and progrotrin contamination (Agerbirk et al., 2014; Felker et al., 2016; Radulovic et al., 2017). Clearly, the natural enantiomer of goitrin in Brassica napus should be used for testing relevant plants for a suitable OATase.

\subsection{Candidate genes for turnover of glucosinolates in intact B. vulgaris plants}

As a follow-up on the hypothesis above (stating that the putative OATase is involved in turnover of OAT after glucosinolate turnover in intact plants) (Figure 2A), we decided to search for candidate genes for initiation of glucosinolate turnover. The B. vulgaris genome (Byrne et al., 2017) and transcriptomes (Wei et al., 2013; Zhang et al., 2015) were mined for orthologs to the genes from Arabidopsis thaliana and Brassica rapa known or suggested to be involved in glucosinolate turnover in intact plants (Klein and Sattely, 2017). A phylogenetic tree was constructed for a first overview of similarities and differences (Figure 10). Two $\beta$ glucosidases named "brassinin-associated $\beta$-glucosidases" (BABG.a and BABG.b) were both suggested to be thioglucoside glucohydrolases able to activate indole glucosinolates for biosynthesis of the indole phytoalexin brassinin in B. rapa (Klein and Sattely, 2017). Interestingly, $B A B G$ orthologs are not found in $A$. thaliana while one $B A B G$ gene was found in the $B$. vulgaris genome on contig 4243.

The "atypical myrosinase" PEN2 (PENETRATION2) has been found to metabolize glucosinolates in $A$. thaliana (Bednarek et al., 2009; Clay et al., 2009). In B. rapa and A. thaliana only one PEN2 gene (orthologous) has been identified. In the $B$. vulgaris genome also only one PEN2 gene was found; BVPEN2 on pseudomolecule 1. This gene was found to be expressed in transcriptomic datasets from both the $\mathrm{P}$ - and G-type of B. vulgaris (Figure 10, Supplementary Table 1).

Both the $A$. thaliana and $B$. rapa genomes possess a gene for a phylogenetic intermediate between PEN2 and BABG, named BGLU27 (Klein and Sattely, 2017). To our knowledge no BGLU27 has been tested and their possible role as myrosinases remains to be studied. In B. vulgaris, two BGLU27 genes were found; BVBGLU27. $a$ and BVBGLU27.b. The BVBGLU27.a gene was localized on the part of the genome currently called pseudomolecule 8 and also found in the transcriptomic dataset from both P and G-type (Figure 10, Supplementary Table 1). In the phylogenetic tree, the BVBGLU27.a protein was situated in a clade also containing AtBGLU27 and BrBGLU27.a and BrBGLU27.c. The B. vulgaris gene is localized on pseudomolecule 7 in the genome, and is phylogenetically closest to BrBGLU27.b.

The phylogenetic tree (Fig. 10) suggested that a common ancestor plant species had at least one copy of each of the three gene families; BGLU27, BABG and PEN2. The clade consisting of the BGLU27 genes has two branches; one including the BGLU27.b genes and one including the BGLU27.a and BGLU27.c genes. Only $B$. rapa has three copies of $B G L U 27$ (a-c), and the phylogenetic analysis suggests a duplication of a common ancestor to the BrBGLU27. $a$ and BrBGLU27.c. genes. A. thaliana has no orthologous gene to $B G L U 27 . b$ and has no copy of the BABG gene, possibly due to gene losses.

The field of glucosinolate turnover in intact plants is in rapid progress (Nakano et al., 2017; Wittstock et al., 2016; Pastorczyk and Bednarek, 2016), and the genes selected for this analysis may only be a subset of relevant glucosinolate hydrolyzing genes. However, the identified genes show that candidates for glucosinolate turnover in intact plants exist and are expressed in B. vulgaris.

\subsection{Perspectives}


In conclusion, resedine is formed from barbarin by a heat sensitive catalyst in crushed tissues of $B$. vulgaris, $N$. officinale and $R$. luteola, but is not detectable in intact plants. As $N$. officinale is a vegetable often eaten raw, resedine will be part of human nutrition at least in the USA where watercress containing glucobarbarin is marketed (Agerbirk et al., 2014). We anticipate the catalyst to be an enzyme, OATase, constitutively expressed in a variety of tissues for turnover of barbarin formed in vivo. The diversity of glucosinolates result in a diverse palette of biological effects, and the diversity is even higher because each glucosinolate can lead to several products (Hayes et al., 2008; Hanschen et al., 2014). Further structural diversity is realized whenever a new type of glucosinolate product is discovered (Agerbirk and Olsen, 2015; Pagnotta et al., 2017; Hanschen et al., 2018). Indeed, turnover of OATs to OAOs could be a general reaction happening for several or all of the around 14 known $\beta$-hydroxylated glucosinolate side chains (Fahey et al., 2001; Agerbirk and Olsen, 2012; Olsen et al., 2016). OAOs were not detected in a recent, very thorough survey of glucosinolate products in cabbages (Hanschen and Schreiner, 2017). However, autolysis was only allowed for $0.5 \mathrm{~h}$, and $\beta$-hydroxylated glucosinolates were not prominent.

Further inducibility of the OATase was not tested. The reaction could be simply a detoxification involved in glucosinolate turnover, possibly allowing sulfur recycling (Maruyama-Nakashita, 2017). Considering the range of bioactivities of other known OAOs, the reaction could also be involved in defense, signaling (Malinowski et al., 2017) or biosynthesis. Biosynthesis might lead to products related to non-indole phytoalexins that are known from $B$. vulgaris and $N$. officinale and suggested to be products of glucosinolate turnover (Pedras and To, 2015; Pedras et al., 2015). As the enzyme activity was detected in two plant families, it could be a widespread enzyme involved in turnover of OATs in the Brassicales. Detoxification of contaminating OATs in cruciferous protein would be a potential industrial application of such an enzyme.

Elemental composition and a UV spectrum so far constitute the only documentation to support formation of the hypothetic thioamide product " 5 " from glucobarbarin (Austin et al., 1068a). However, the general formation of thioamides is better documented (Austin et al., 1968b). Austin et al. (1968a) reported high yields of thioamide from $\beta$-hydroxylated glucosinolates but lack of thioamide from a non-hydroxylated glucosinolate, and suggested a mechanism involving the hydroxy group. These authors reported $40 \%$ molar yields of the thioamide from epiprogoitrin. However, later authors (Bellostas et al., 2008) reported around tenfold lower yields and the identification of the thioamide was not conclusive. Furthermore, analytical proof, i.e. GC-MS and comparison with an authentic reference, was recently reported for formation of the thioamide from a glucosinolate lacking a hydroxy group (3-methoxybenzylglucosinolate) (Stevens et al., 2009). Hence, formation of thioamides as such from glucosinolates is decently documented, but any influence of the $\beta$-hydroxy group is not. Furthermore, the apparently consistent high yields in the pioneering papers (Austin et al., 1968a and b) contrast with the findings of later authors. It seems as if yet unidentified factors influence formation of thioamides from non-enzymatic, ferrous ion catalyzed breakdown of glucosinolates. As elemental sulfur release is expected to accompany general nitrile formation, for stoichiometric reasons, and as we detected amide formation under such conditions as well, involvement of elemental sulfur or any product in downstream reactions could be hypothesized. From the perspective of glucobarbarin biology, the results reported here show that formation of a suggested thioamide from glucobarbarin is not easily reproduced and was apparently not of importance at a range of biologically relevant conditions. The latter result had been predicted in a review article (Bones and Rossiter, 2006). 
As resedine is not accumulated in intact plants, further metabolism is anticipated in vivo. This scenario requires turnover of the precursor glucosinolate in intact plants, and a variety of candidate genes for such turnover were identified in $B$. vulgaris. Tissue-specific biosynthesis and storage of glucosinolates is well described (Nintemann et al., 2018). Localization of a putative OATase could pinpoint sites of turnover. As an alternative to classical isolation and sequencing, we suggest that co-expression analysis (e.g. Yang et al., 2017; Nakano et al., 2017; Pislewska-Bednarek et al., 2018), using the identified genes as leads (Figure 10), could identify the OATase and other enzymes involved in glucosinolate turnover in intact plants.

\section{Experimental}

\subsection{Plants}

Seeds of the G-type of B. vulgaris R. Br. were of accession B44, using a batch propagated by the author NA in 2008 (Agerbirk et al., 2003). The plants used for the experiments were grown in loamy soil in a sunny garden, and were large second year plants with fresh, healthy-looking upper leaves and green siliques. Seeds of the analyzed plants have been deposited at Nordgen (www.nordgen.org/sesto), publicly available with accession number NGB31789. Samples for the experiments described here were taken in April-June 2017 and transported and stored in plastic bags until use later the same day. Due to lack of additional seeds of the same accession, seeds of B. vulgaris (G-type) were from the accession Hedeland 2010 (Heimes, 2016). Reseda luteola plants were from the permanent plant collection at Dept. of Plant and Environmental Sciences, KU, and the identity confirmed from morphology by NA. Fresh, green branches with leaves were harvested from flowering plants in June 2017 and transported in plastic bags until dissection into leaves and shoot axes about $1 \mathrm{~h}$ later. Seeds of $R$. luteola and $R$. odorata were from Chiltern Seeds, Wallingford, UK.

\subsection{Glucosinolates, oxazolidine-2-thiones and nitriles}

The glucosinolates (GSLs) glucobarbarin (1) ((S)-2-hydroxy-2-phenylethylGSL) (with minor impurities of epiglucobarbarin and phenethyIGSL) and epiprogoitrin ((R)-2-hydroxybut-3-enyIGSL) were isolated as $\mathrm{K}^{+}$ salts from ripe seeds of $B$. vulgaris and Crambe abyssinica, respectively, by extraction of the defatted seed meal with boiling $70 \%$ ethanol followed by ion exchange chromatography followed by gel filtration chromatography, essentially as described previously (Bernadi et al., 2003) with some minor modifications (Haack et al., 2010). Seeds of B. vulgaris and C. abyssinica for the purification were from the crucifer collection at CREA-CI, Bologna, Italy (Lazzeri et al., 2013). The substrates (-)-(S)-5-ethyl-5-methylOAT (9) and (S)-goitrin, (-)-(S)-5-vinylOAT (11), were prepared by myrosinase-catalyzed hydrolysis of glucocleomin, (S)-2hydroxy-2-methylbutyIGSL and epiprogoitrin, as described by Leoni et al. (1999). Barbarin (5-phenylOAT) (2) was the previously reported preparation (Agerbirk and Olsen, 2012). The nitriles 6 (4hydroxyphenylacetonitrile) and $\mathbf{7}$ (2-hydroxy- (4-hydroxyphenyl)acetonitrile) were the previously reported preparations from sulfatase-treated caterpillar frass (Agerbirk et al., 2010).

\subsection{Glucosinolate analysis}

GSLs were determined directly or as desulfated derivatives ("desulfoGSL method"). HPLC-DAD of intact GSLs was carried out using eluents acidified with $\mathrm{CF}_{3} \mathrm{COOH}$ at $0.1 \%$, exactly as previously described (Agerbirk and Olsen, 2012). For logistic reasons, some routine control of GSL hydrolysis was carried out using formic acid at the same concentration (0.1\%), giving increased tailing but still sufficiently sharp peaks for integration. The desulfoGSL method was carried out in two laboratories at slightly different conditions. In the Bologna lab for isolation work, conditions were as reported by Pagnotta et al. (2017). In the 
Copenhagen lab, for determination of GSL profiles of Reseda species, HPLC-MS/MS analysis after enzymatic desulfation was carried out as reported by Olsen et al. (2016).

\subsection{Myrosinase-catalyzed glucosinolate hydrolysis in vitro using isolated components}

The GSL ( $24 \mathrm{nmol}, 0.15 \mathrm{mM}$ ) and myrosinase (from Sinapis alba, Sigma, T4528) (72 $\mu \mathrm{g}, 30 \mathrm{mU}$ ) were dissolved in either of two buffered solvents prepared for OAT or nitrile formation, respectively. The OATstimulating solvent was $38 \mathrm{mM}$ potassium phosphate $\mathrm{pH} \mathrm{7}$, and the nitrile-stimulating solvent was $60 \mathrm{mM}$ aq. sodium acetate $\mathrm{pH} 5$ with added ascorbic acid $(5 \mathrm{mM})$ and $\mathrm{FeSO}_{4}(2.5 \mathrm{mM})$. Each reaction mixture was incubated at ambient temperature $\left(20^{\circ} \mathrm{C}\right)$ overnight in a total of $160 \mu \mathrm{l}$. An aliquot was taken, $\mathrm{MeOH}$ added to $20 \%$, the mixture was centrifuged and tested by HPLC-DAD for confirmation of complete disappearance of intact glucosinolate, and for hydrolysis products by ion trap HPLC-MS (Section 3.6.).

\subsection{Ferrous ion-catalyzed non-enzymatic glucobarbarin breakdown}

Glucobarbarin ( $3 \mu \mathrm{mol}, 15 \mathrm{mM}$ final conc.) was incubated for $22 \mathrm{~h}$ in $150 \mathrm{mM}$ aq. $\left(\mathrm{NH}_{4}\right)_{2} \mathrm{Fe}\left(\mathrm{SO}_{4}\right)_{2}, 45 \mathrm{mM}$ sodium acetate buffer $\mathrm{pH} 5$, in a total of $200 \mu \mathrm{l}$. A rust-red precipitate was observed. A sample (30 $\mu \mathrm{l})$ of the liquid phase was taken after incubation, diluted tenfold with $20 \% \mathrm{MeOH}$, centrifuged and analyzed by HPLC for intact glucosinolates, confirming extensive glucobarbarin degradation. The extent of degradation was calculated from peak areas, comparing with an aliquot of intact glucobarbarin stock not subjected to the ferrous salt and diluted in parallel to the ferrous-salt treated aliquot. The same sample was analyzed by HPLC-DAD, searching at $210 \mathrm{~nm}$ and $267 \mathrm{~nm}$ for the hypothetic thioamide " 5 ". For further analysis and peak isolation, the remaining $170 \mu \mathrm{l}$ was repeatedly extracted with ethyl acetate. The organic phase was evaporated and the residue dissolved in $800 \mu \mathrm{l} 20 \%$ aq. $\mathrm{MeOH}$ and centrifuged. The supernatant was analyzed and two dominant peaks (4 and $\mathbf{8}$, Figure 5 ) and four tiny peaks isolated by HPLC-DAD (Section 3.8). The entire organic fraction and the collected peaks were analyzed by ion trap HPLC-MS for identification and search for " $\mathbf{5}$ ". The two major peaks, $\mathbf{4}$ and $\mathbf{8}$, were also subjected to HPLC-QqToF-MS. The experiments were carried out in March, 2017, before the handling of $B$. vulgaris homogenates and of $\mathrm{H}_{2} \mathrm{O}_{2}$ described in subsequent sections. Likewise, other oxidative reagents were not handled in the laboratory in parallel.

\subsection{Determination of glucobarbarin products by ion trap HPLC-MS}

Ion trap HPLC-MS/MS of hydrolysis products from glucobarbarin was carried out using a C18 column and a Bruker HCT-Ultra ion trap detector as previously reported (Agerbirk et al., 2015; Agerbirk and Olsen 2015), except that the MS settings were optimized for increased sensitivity and MS2 fragmentation of this $\mathrm{m} / \mathrm{z}$ range (target mass, $180 \mathrm{~m} / \mathrm{z}$; precursor selection, 100-300 m/z; scan range 100-400 m/z) (Supplementary Figure 5D), that UV data were collected (sum of absorption from 190-700 $\mathrm{nm}$ as well as DAD spectra) and that the eluent $A$ and gradient were slightly modified. The mobile phases were: $A$, water with $0.1 \%(v / v)$ $\mathrm{HCOOH}$ and $10 \mu \mathrm{M} \mathrm{NaCl} ; \mathrm{B}$, acetonitrile with $0.1 \%(\mathrm{v} / \mathrm{v}) \mathrm{HCOOH}$. The gradient program was: 0 to $1 \mathrm{~min}$, isocratic $2 \%$ B; 1 to $8 \mathrm{~min}$, linear gradient $2 \%$ to $40 \%$ B; 8 to 9 min, linear gradient $40 \%$ to $90 \%$ B; 9 to 11.5 isocratic $90 \% \mathrm{~B} ; 11.60$ to $14 \mathrm{~min}$, isocratic $2 \% \mathrm{~B}$. The flow rate was generally $0.2 \mathrm{ml} / \mathrm{min}$ but was increased to $0.3 \mathrm{ml} / \mathrm{min}$ between 11.5 and $13.5 \mathrm{~min}$.

The relative levels of $2, \mathbf{3}, \mathbf{4}$ and $\mathbf{8}$ were calculated from peak intensities at the relevant retention time in extracted ion chromatograms of the major ions in each spectrum, i.e. $m / z 202,180,164,120\left(2, t_{R} 8.0 \mathrm{~min}\right)$, $\mathrm{m} / \mathrm{z}$ 186, 164, 146, 120 (3, $\left.\mathrm{t}_{\mathrm{R}} 7.0 \mathrm{~min}\right), \mathrm{m} / \mathrm{z}$ 170, 148, 130 (4, $\left.\mathrm{t}_{\mathrm{R}} 6.4 \mathrm{~min}\right)$, and $\mathrm{m} / \mathrm{z} 188\left(8, \mathrm{t}_{\mathrm{R}} 4.3 \mathrm{~min}\right)$, taking reduced molar detector response of the nitrile 4 into account by dividing the peak intensity with 0.11 and of the amide 8 by dividing the peak intensity with 0.64 (Section 3.7). Considering the similar structures of 2 
and 3, their MS-detector responses were assumed to be equal when all four major ions above were integrated, in accordance with observed stable total concentration of the two (Table 2).

\subsection{Detector calibration for nitrile and amide products}

The molar UV-detector response of the nitrile $\mathbf{4}$ derived from $\mathbf{2}$ was calculated from the increase of the nitrile peak and the decrease of the barbarin peak in HPLC-DAD, both at $210 \mathrm{~nm}$, in controlled hydrolysis experiments with and without added $\mathrm{FeSO}_{4}$. The molar peak area of 3-hydroxy-3-phenylpropanenitrile (4) was on average $51 \%$ of the molar peak area of barbarin, both at $210 \mathrm{~nm}$, allowing calculation of levels of the nitrile in simple samples based on the barbarin standard curve and this factor. For complex samples, the HPLC-MS analysis was needed, and this analysis was calibrated with the same sample used for UV calibration (Figure 3). The molar MS detector response of the nitrile 4 base peak $(\mathrm{m} / \mathrm{z} 130$ ) was on average $15 \%$ of the response of the barbarin base peak $(\mathrm{m} / \mathrm{z} 180)$. Combining all major MS peaks to obtain increased sensitivity ( $\mathrm{m} / \mathrm{z}$ 170, 148 and 130 for 4 , and $\mathrm{m} / \mathrm{z} 202,180,146$ and 120 for 2 ), the molar MS detector response of $\mathbf{4}$ was $11 \%$ of the molar detector response of $\mathbf{2}$.

The MS detector response of 3-hydroxy-3-phenylpropaneamide (8) was estimated from comparison of HPLC-DAD and HPLC-MS of a mixed sample (Figure 5B), assuming equal UV response of $\mathbf{4}$ and $\mathbf{8}$ at $210 \mathrm{~nm}$. In this way, the molar response of the amide $(\mathrm{m} / \mathrm{z} 188$ trace) was estimated to approximately $64 \%$ of the detector response of 2 (combining $\mathrm{m} / \mathrm{z}$ traces 202, 180, 146 and 120).

\subsection{HPLC-DAD of glucobarbarin products and isolation of breakdown products due to a ferrous salt}

Hydrolysis products in $20 \%$ aq. MeOH were separated by HPLC-DAD (Agerbirk et al., 2014). Briefly, the column had a phenylhexyl stationary phase and we used a 2 min isocratic period with $100 \% \mathrm{H}_{2} \mathrm{O}$ followed by a $48 \mathrm{~min}$ linear gradient over from 0 to $70 \% \mathrm{MeOH}$. The injection volume was $100 \mu \mathrm{l}$. UV-data from 210 to $370 \mathrm{~nm}$ were collected, and chromatograms at specific detection wavelengths prepared according to the analyte searched for ( $210 \mathrm{~nm}$ for 2, 3, 4, hypothetic " 5 ", and 8; $267 \mathrm{~nm}$ for hypothetic 5; $240 \mathrm{~nm}$ for 2). For identification of products of ferrous salt catalyzed breakdown, peaks of $\mathbf{4}$ and $\mathbf{8}$ collected from two consecutive runs were pooled and analyzed by ion trap HPLC-MS and high resolution HPLC-QqToF -MS.

\subsection{High resolution HPLC-QqToF-MS}

Isolated products and crude synthesis samples in $\mathrm{H}_{2} \mathrm{O}$ or $20 \%$ aq. $\mathrm{MeOH}$ were analyzed by liquid chromatography coupled to quadrupole time-of-flight mass spectrometry. A Dionex UltiMate ${ }^{\mathrm{TM}} 3000 \mathrm{RS}$ UPLC system from Thermo Scientific ${ }^{\mathrm{TM}}$ (Waltham, MA USA) was used and equipped with a Kinetex XB-C18 column $(2.1 \mathrm{~mm} \times 100 \mathrm{~mm}, 1.7 \mu \mathrm{m}$, Phenomenex). The injection volume was $5 \mu$ l. Mobile phase A was MilliQ water with $0.05 \%$ formic acid, whereas mobile phase B was acetonitrile with $0.05 \%$ formic acid. The 20 min stepwise linear gradient was $\mathrm{t}=0 \mathrm{~min}, 2 \% \mathrm{~B} ; \mathrm{t}=10 \mathrm{~min}, 60 \% \mathrm{~B} ; \mathrm{t}=12 \mathrm{~min}, 60 \% \mathrm{~B} ; \mathrm{t}=13 \mathrm{~min}, 2 \% \mathrm{~B} ; \mathrm{t}=20$ $\min , 2 \%$ B. The flow rate was $0.3 \mathrm{ml} / \mathrm{min}$. For detection, a Bruker Compact QqTOF mass spectrometer (Bremen, Germany) was used and operated in positive mode. The MS settings were: dry temperature $220^{\circ} \mathrm{C}$, dry gas flow rate $8 \mathrm{l} / \mathrm{min}$, capillary $4000 \mathrm{~V}$, collision energy $7 \mathrm{eV}$ and collision RF $500 \mathrm{Vpp}$, transfer time 100 $\mu \mathrm{s}$, pre-pulse storage $5 \mu \mathrm{s}$. The QqTOF was operated with mass range set from 50 to $1200 \mathrm{~m} / \mathrm{z}$ and was calibrated with sodium formate clusters at the beginning of every injection. Acquisition of LC-MS data was performed in Bruker DataAnalysis 4.3.

\subsection{Autolysis experiments}

Leaves or siliques ( $0.5 \mathrm{~g}$ fresh weight, rinsed with a brush for any macroscopic impurities) were homogenized in a porcelain mortar and the total homogenate transferred to a $20 \mathrm{ml}$ glass beaker with lid. 
The homogenate was incubated at ambient temperature $\left(20-25^{\circ} \mathrm{C}\right)$ at the intended autolysis time. For experimental variation of conditions, individual assays were incubated in parallel but slightly displaced for logistic reasons. After the intended autolysis time, the beaker was put on a hot-plate and $8 \mathrm{ml}$ of preheated, boiling $20 \%$ aq. $\mathrm{MeOH}$ was added for boiling extraction for 1 minute (moving beaker on and off to avoid vigorous boiling), followed by centrifugation ( $4000 \mathrm{~g}, 5 \mathrm{~min}$ ). The supernatant was added solvent to $10.0 \mathrm{ml}$ in a volumetric cylinder followed by mixing. A $1.4 \mathrm{ml}$ sample was taken for freezing $\left(-20^{\circ} \mathrm{C}\right)$ overnight (for settling of any debris), thawed and subjected to additional centrifugation ( $6000 \mathrm{~g}, 3 \mathrm{~min})$. The resulting sample was suitable for HPLC-DAD analysis (Agerbirk et al., 2014), used for some samples but not reported quantitatively. Before HPLC-MS, used for all reported quantitative results, a further 5.00 fold dilution in $20 \%$ aq. $\mathrm{MeOH}$ was done. For other plant parts, seeds and seedlings, lower fresh weight had to be used resulting in lower sensitivity, and for seeds water was added during homogenization (Table 1).

For the experiment reported in Figure 7B, a combined leaf homogenate was first allowed to autolyze ( $0.3 \mathrm{~h})$ for formation of barbarin, during which time the homogenate was distributed in six similar $0.50 \mathrm{~g}$ aliquots in beakers. Each aliquot was mixed with $3.0 \mathrm{ml}$ sodium phosphate buffer $(0.1 \mathrm{M}, \mathrm{pH}$ 7), then incubated for a total of $25 \mathrm{~h}$. During this incubation, the aliquots were subjected to brief $(1 \mathrm{~min}$ ) boiling at various times. Samples were boiled (pairwise) after either $0.3 \mathrm{~h}, 6.3 \mathrm{~h}$ or $24.3 \mathrm{~h}$, followed by continued incubation until usual hot extraction of all portions after $25 \mathrm{~h}$ and preparation for ion trap HPLC-MS analysis as in the general protocol.

\subsection{Isolation and NMR of resedine}

Pooled extracts ( $30 \mathrm{ml}$ ) of crushed upper leaves and siliques (in total $2 \mathrm{~g}$ fresh wt.) of $B$. vulgaris, allowed to autolyze for $24 \mathrm{~h}$, were concentrated to $8 \mathrm{ml}$ under a gentle air-stream to remove $\mathrm{MeOH}$ and simplify loading. Two solid phase extraction cartridges (Supelclean C18, $500 \mathrm{mg}$, Supelco) were activated with each $3 \mathrm{ml} \mathrm{MeOH}$ and equilibrated with $3 \mathrm{ml} \mathrm{H}_{2} \mathrm{O}$. The extract was split in two and loaded on the cartridges, which were each eluted stepwise with $3 \mathrm{ml}$ each of $10 \%$ aq. $\mathrm{MeOH}, 20 \%$ aq. $\mathrm{MeOH}, 70 \%$ aq. $\mathrm{MeOH}, 100 \%$ aq. $\mathrm{MeOH}$. Resedine (3) and $\mathbf{2}$ were both found in the $70 \% \mathrm{MeOH}$ fraction. This fraction was concentrated under a gentle air stream until near dryness, and brought to $3 \mathrm{ml}$ of $20 \%$ aq. $\mathrm{MeOH}$. Resedine was isolated by repeated prep. HPLC from this fraction, using the usual HPLC equipment (Agerbirk and Olsen, 2011) (Supplementary Figure 2) fitted with a 'Luna' phenylhexyl column $(25 \mathrm{~cm} \times 4.6 \mathrm{~mm}, 5 \mu \mathrm{m})$ (Phenomenex, Torrance, CA, USA). The injection volume was $400 \mu \mathrm{l}$. After $2 \mathrm{~min}$ at $100 \% \mathrm{H}_{2} \mathrm{O}$, a linear gradient in $\mathrm{MeCN}$ was applied, from $0-35 \%$ in 28 min, followed by a brief wash and equilibration in $\mathrm{H}_{2} \mathrm{O}$. Resedine eluted at 22 min, a few min after a group of numerous other peaks, while 2 eluted at $32 \mathrm{~min}$. Resedine for NMR was obtained by freeze drying after partial evaporation under a gentle air stream. The proton NMR spectrum of resedine was recorded on an AVANCE III 600 spectrometer equipped with a TCI cryoprobe. The sample was dissolved in $\mathrm{CDCl}_{3}$ and the temperature set at $298 \mathrm{~K}$ during data acquisition. The spectrum was referenced at $7.26 \mathrm{ppm}$ for the residual protonated signal. PERCH spectral analysis started with the building of a 3D model of the resedine molecular structure by means of MMS, the modeling tool integrated in PERCH. The predicted chemical shift and coupling constant values inferred from the 3D model were iteratively refined so that the corresponding calculated spectrum matched at best the experimental one (Laatikainen et al., 1996). 


\subsection{Synthetic conversion of oxazolidine-2-thiones into oxazolidin-2-ones}

Conversion of OATs to OAOs by treatment with $\mathrm{H}_{2} \mathrm{O}_{2}$ had been reported (Evans and Weber, 1987; MorenoMañas and Padros, 1993), and was conducted by incubation of $2(20 \mu \mathrm{M})$ in up to $8 \%$ aq. $\mathrm{H}_{2} \mathrm{O}_{2}$ overnight. We observed complete conversion of $\mathbf{2}$ into resedine (3) (CAS 7693-77-8) and a more polar product (around 1:1 judged from HPLC-DAD area at $210 \mathrm{~nm}$ ). Moderate variation of the conditions, with $\left[\mathrm{H}_{2} \mathrm{O}_{2}\right]$ ranging from $0.8-8 \%$ and reaction times ranging from $4 \mathrm{~h}$ to $18 \mathrm{~h}(\mathrm{~N}=5)$, had no significant effect on product profile (Figure 11). The intended product was found identical to 3 from B. vulgaris and R. luteola by ion trap HPLCMS/MS. High resolution MS confirmed the molecular formula (found: $164.0704[\mathrm{M}+\mathrm{H}]^{+}$, calculated for $\mathrm{C}_{9} \mathrm{H}_{10} \mathrm{O}_{2} \mathrm{~N}$ : 164.0706. High resolution MS also confirmed that the major fragments were due to loss of $\mathrm{H}_{2} \mathrm{O}$ and $\mathrm{CO}_{2}$ (Supplementary figure 7). The more polar product was tentatively identified as 2-amino-1phenylethanol, a previously suggested breakdown product of barbarin (Lutfullin et al., 1976), by ion trap HPLC-MS/MS (Figure 11) and high resolution HPLC-MS (found: $138.0913[\mathrm{M}+\mathrm{H}]^{+}$, calculated for $\mathrm{C}_{8} \mathrm{H}_{12} \mathrm{ON}^{+}$: 138.0913; found: $120.0804\left[\mathrm{M}-\mathrm{H}_{2} \mathrm{O}+\mathrm{H}\right]^{+}$, calculated for $\left.\mathrm{C}_{8} \mathrm{H}_{10} \mathrm{~N}^{+}: 120.0808\right)$. Exclusive formation of the proton adduct, not the sodium adduct, supported an amine functional group, and loss of water in MS2 supported a hydroxyl group.

Two other OATs were available, $(R)$-5-vinylOAT ((R)-goitrin) and (S)-5-ethyl-5-methylOAT. For use as references below, they were also converted into OAOs by incubation overnight with aq. $1 \% \mathrm{H}_{2} \mathrm{O}_{2}$. The identity of the authentic reactant 5-ethyl-5-methylOAT was confirmed by ion trap HPLC-MS/MS, $m / z 146$ $[\mathrm{M}+\mathrm{H}]^{+}$(with major loss of $\mathrm{H}_{2} \mathrm{~S}$ in MS2), $\mathrm{m} / z 168[\mathrm{M}+\mathrm{Na}]^{+}$, and high res. HPLC-MS/MS (found: 146.0637, calculated for $\mathrm{C}_{6} \mathrm{H}_{12} \mathrm{NOS}^{+}:$146.0634). The major product 5-methyl-5-ethylOAO was tentatively identified in ion trap HPLC-MS: $m / z 130[\mathrm{M}+\mathrm{H}]^{+}$(with major loss of $\mathrm{H}_{2} \mathrm{O}$ in MS2), $m / z 152[\mathrm{M}+\mathrm{Na}]^{+}$and high res. HPLC-MS (found: 130.0867 , calculated for $\mathrm{C}_{6} \mathrm{H}_{12} \mathrm{NO}_{2}^{+}:$130.0863) (Supplementary Figure 8).

Likewise, the identity of the authentic reactant (R)-5-vinylOAT was confirmed by ion trap HPLC-MS/MS and high res. HPLC-MS/MS (found: 130.0318, calculated for $\mathrm{C}_{5} \mathrm{H}_{8} \mathrm{NOS}^{+}: 130.0321$ ). The major product 5vinylOAO was tentatively identified in ion trap HPLC-MS: $m / z 114[\mathrm{M}+\mathrm{H}]^{+}, m / z 136[\mathrm{M}+\mathrm{Na}]^{+}$and high res HPLC-MS (found: 114.0546, calculated for $\mathrm{C}_{5} \mathrm{H}_{8} \mathrm{NO}_{2}{ }^{+}:$114.0550) (Supplementary Figure 9). For these latter $\mathrm{OAO}$ syntheses, the corresponding amino-alcohols were apparently not major side-products of the oxidative conversion from OAT to $\mathrm{OAO}$ by $\mathrm{H}_{2} \mathrm{O}_{2}$, but other polar side-products were detected.

\subsection{Spiking with potential oxazolidinase substrates}

For each experiment, a number of $B$. vulgaris upper leaves (4-8) were pooled and homogenized (in a mortar at room temperature) in order to minimize biological variation between individual assays. For testing of various OAO precursors, four 0.10 aliquots of leaf homogenate were distributed in each of four $10 \mathrm{ml}$ beakers, mixed with either $0.10 \mathrm{ml}$ water (control), aq. $(R)$-goitrin $(4 \mathrm{mg} / \mathrm{ml})$, aq. epiprogoitrin $(8 \mathrm{mg} / \mathrm{ml})$ or aq. (S)-5-ethyl-5-methylOAT $(4 \mathrm{mg} / \mathrm{ml})$. In a further four beakers, water and the same potential substrate solutions were mixed $1: 1$ with $50 \mathrm{mM}$ aq. sodium acetate buffer $\mathrm{pH} 5$ as a control, and also incubated in parallel. After gentle mixing with a pipette tip, each beaker was covered with a lid and incubated in parallel for $2 \mathrm{~h}$. Then, beakers were put on a hot-plate, $2 \mathrm{ml}$ boiling water was added, and hot extraction carried out for $1 \mathrm{~min}$. This experiment was carried out in duplicate on two different days, except for the epiprogoitrin experiment that was not repeated.

For testing heat sensitivity, half of the total leaf homogenate was heated for $4 \mathrm{~min}$ in a test tube immersed in a boiling water bath. From the heated part, four $0.10 \mathrm{~g}$ aliquots were distributed in each of four $10 \mathrm{ml}$ beakers, mixed with either aq. $(S)-5$-ethyl-5-methylOAT $(4 \mathrm{mg} / \mathrm{ml})(\mathrm{N}=2)$ or $0.10 \mathrm{ml}$ water (control) $(\mathrm{N}=2)$. From the remaining, non-heated part, four $0.10 \mathrm{~g}$ aliquots were also distributed in four beakers and added 
the same amounts of the OAT solution or water $(\mathrm{N}=2+2)$. In a further four beakers, the same OAT solution or water was mixed 1:1 with $50 \mathrm{mM}$ aq. sodium acetate buffer as a control, and also incubated in parallel $(\mathrm{N}=2+2)$. After gentle mixing with a pipette tip, each beaker was covered with a lid and incubated in parallel for $2 \mathrm{~h}$. Then, beakers were put on a hot-plate, $2 \mathrm{ml}$ boiling water was added, and hot extraction carried out for $1 \mathrm{~min}$.

From both experiments, the entire material after boiling extraction was taken to $2.0 \mathrm{ml}$ and mixed. A sample was centrifuged ( $6000 \mathrm{~g}, 4 \mathrm{~min}$ ) and the supernatant taken to ion trap HPLC-MS analysis. Care was taken in all experiments to make sure that $\mathrm{H}_{2} \mathrm{O}_{2}$ contamination could be completely ruled out as a factor. Analysis of enzyme assay products was carried out before analysis of $\mathrm{OAO}$ references containing surplus $\mathrm{H}_{2} \mathrm{O}_{2}$ to make sure that contamination with $\mathrm{H}_{2} \mathrm{O}_{2}$ could not happen in the HPLC autosampler either. Lack of $\mathrm{OAO}$ production from homogenate alone, observation of barbarin and resedine as endogenous metabolites (also in heated control due to reaction before heating), and positive OAO production from (S)-5-ethyl-5methylOAT, goitrin, and progoitrin were all consistent.

\subsection{Bioinformatics.}

The B. vulgaris G-type genome (Byrne et al. 2017) and transcriptome (Wei et al. 2013) and P-type transcriptome (Zhang et al. 2015) were mined using genes previously described by Klein and Sattely (2017). The sequences were collected from phytozome: Arabidopsis thaliana (At1g47600, At2g44490, At3g60120); Brassica rapa (Brara.E00435, Brara.E00428, Brara.I04143, Brara.D02695, Brara.E00436, Brara.D00184 (truncated version, so we used XM 009140622.1 from NCBI)). The sequences found in the $B$. vulgaris genome have not yet received a GeneID, but are available as supplementary data with this paper.

Nucleotide sequences of the candidate genes from B. vulgaris and the collection of genes from $A$. thaliana and B. rapa (Supplementary Table 1) were analyzed in MEGA6 (Tamura et al. 2013). Intron/exon structures from $B$. vulgaris genomic candidate genes were predicted by comparison with $B$. vulgaris transcripts or $A$. thaliana homologs. Protein sequences of the candidate genes from the $B$. vulgaris $\mathrm{G}$-type genome and the collection of genes from $A$. thaliana and $B$. rapa were aligned using muscle and standard parameters in MEGA6 (Tamura et al. 2013). Due to different sequence length the phylogenetic analysis was constructed based on position 170 to position 563 in the amino acid residue alignment (Supplementary Table 2). The phylogenetic tree (Figure 10) was inferred by using the Maximum Likelihood method based on the JTT matrix-based model (Jones et al. 1992). The tree with the highest log likelihood (-3049.6303) is shown. Initial tree(s) for the heuristic search were obtained automatically by applying Neighbor-Join and BioNJ algorithms to a matrix of pairwise distances estimated using a JTT model, and then selecting the topology with superior log likelihood value. A discrete Gamma distribution was used to model evolutionary rate differences among sites ( 5 categories) $(+G$, parameter $=0.6003)$.

Author contributions. Conceived study: NA, CM, LL, PR. Did MS incl. optimization: AM, EL, NA. Did and interpreted NMR: JMN. Isolated glucosinolates and provided non-Barbarea OATs: LU, SC, LL. Did bioinformatics: $P \emptyset \mathrm{E}$ supervised by SB. Did remaining experiments, interpreted $\mathrm{MS}$ and noticed resedine: NA. Wrote draft: NA. Wrote paper: All.

Acknowledgements. We thank Ms. Linda E. Hertz for growing R. luteola and Fernando Geu-Flores and Mika Zagrobelny for discussions. Financial support from Torben and Alice Frimodts Fond, from CNRS, Conseil Regional Champagne Ardenne, Conseil General de la Marne, Ministry of Higher Education and Research (MESR) and EU-programme FEDER to the PIAneT CPER project, is gratefully acknowledged. 


\section{References}

Agerbirk, N., Olsen, C. E., Topbjerg, H. B., Sørensen, J. C., 2007. Host plant dependent metabolism of 4hydroxybenzylglucosinolate in Pieris rapae: substrate specificity and effects of genetic modification and plant nitrile hydratase. Insect Biochem. Mol. Biol. 37, 1119-1130.

Agerbirk, N., Olsen, C.E., Poulsen, E., Jacobsen, N., Hansen, P.R., 2010b. Complex metabolism of aromatic glucosinolates in Pieris rapae caterpillars involving nitrile formation, hydroxylation, demethylation, sulfation, and host plant dependent carboxylic acid formation. Insect Biochem. Mol. Biol. 40, 126-137.

Agerbirk, N., Olsen, C.E., 2011. Isoferuloyl derivatives of five seed glucosinolates in the crucifer genus Barbarea. Phytochemistry 72, 610-623.

Agerbirk, N., Olsen, C.E., 2012. Glucosinolate structures in evolution. Phytochemistry 77, 16-45.

Agerbirk, N., Olsen, C.E., Cipollini, D., Ørgaard, M., Linde-Laursen, I., Chew, F.C., 2014. Specific glucosinolate analysis reveals variable levels of glucobarbarins, dietary precursors of 5-phenyloxazolidine-2-thiones, in watercress types with contrasting chromosome number. J. Agric. Food Chem. 62, 9586-9596.

Agerbirk, N., Olsen, C.E., 2015. Glucosinolate hydrolysis products in the crucifer Barbarea vulgaris include a thiazolidine-2-one from a specific phenolic isomer as well as oxazolidine-2-thiones. Phytochemistry 115, 143-151.

Agerbirk, N., Olsen, C.E., Heimes, C., Christensen, S., Bak, S., Hauser, T., 2015. Multiple hydroxyphenethyl glucosinolate isomers and their tandem mass spectrometric distinction in a geographically structured polymorphism in the crucifer Barbarea vulgaris. Phytochemistry 115, 130-142.

Austin, F. L., Gent, C. A., Wolff, I. A. , 1968a. Degradation of natural thioglucosides with ferrous salts. J. Agric. Food Chem. 16, 752-755.

Austin, F.L., Gent, C.A., Wolf, I.A., 1968b. Enantiomeric 3-hydroxypent-4-enethionamides from thioglucosides of Crambe and Brassica seeds by action of ferrous salts. Can. J. Chem. 46, 1507-1512.

Bednarek, P., Piślewska-Bednarek, M., Svatoš, A., Schneider, B., Doubský, J., Mansurova, M., Humphry, M., Consonni, C., Panstruga, R., Sanchez-Vallet, A., Molina, A., Schulze-Lefert, P., 2009. A glucosinolate metabolism pathway in living plant cells mediates broad-spectrum antifungal defense. Science 323, 101106.

Bellostas, N., Sørensen, A.D., Sørensen, J.C., Sørensen, H., 2008. Fe ${ }^{2+}$-catalyzed formation of nitriles and thionamides from intact glucosinolates. J. Nat. Prod. 71, 76-80.

Bernardi R., Finiguerra M.G., Rossi A.A., Palmieri, S., 2003. Isolation and biochemical characterization of a basic myrosinase from ripe Crambe abyssinica seeds, highly specific for epi-progoitrin. J. Agric. Food Chem. 51, 2737-2744.

Blaževic, I., Montaut, S., Burcul, F., Rollin, P., 2015. Glucosinolates: novel sources and biological potential. In: Mérillon, J.-M., Ramawat, K.G. (Eds) Glucosinolates, Reference Series in Phytochemistry, DOI 10.1007/978-3-319-26479-0_1-1 
Bones, A.M., Rossiter, J.T., 2006. The enzymic and chemically induced decomposition of glucosinolates. Phytochemistry 67, 1053-1067.

Byrne, S., Erthmann, P.Ø., Agerbirk, N., Bak, S., Hauser, T.P., Nagy, I., Paina, C., Asp, T., 2017. The genome sequence of Barbarea vulgaris facilitates the study of ecological biochemistry. Sci. Rep. 7: 40728.

Clay, N. K., Adio, A. M., Denoux, C., Jander, G., Ausubel, F. M., 2009. Glucosinolate metabolites required for an Arabidopsis innate immune response. Science 323, 95-105.

Diekema, D.J., Jones, R.N., 2001. Oxazolidinone antibiotics. Lancet 358, 1975-1982.

Dalby-Brown, L., Olsen, C.E., Nielsen, J.K., Agerbirk, N., 2011. Polymorphism for novel tetraglycosylated flavonols in an eco-model crucifer, Barbarea vulgaris. J. Agric. Food Chem. 59, 6947-6956.

Dekic, M.S., Radulovic, N.S., Stojanovic, N.M., Randjelovic, P.J., Stojanovic-Radic, Z., Najman, S., Stojanovic, S., 2017. Spasmolytic, antimicrobial and cytotoxic activities of 5-phenylpentyl isothiocyanate, a new glucosinolate autolysis product from horseradish (Armoracia rusticana P. Gaertn., B. Mey. \& Scherb., Brassicaceae). Food Chem. 232, 329-339.

Evans, D.A., Bartroli, J., Shih, T.L., 1981. Enantioselective aldol condensations. 2. Erythro-selective chiral aldol condensations via boron enolates. J. Am. Chem. Soc. 103, 2127-2129.

Evans, D. A., Weber, A. E., 1987. Synthesis of the cyclic hexapeptide echinocandin D. New approaches to the asymmetric synthesis of $\beta$-hydroxy amino acids. J. Am. Chem. Soc. 109, 7151-7157.

Felker, P., Bunch, R., Leung, A.M., 2016. Concentrations of thiocyanate and goitrin in human plasma, their precursor concentrations in brassica vegetables, and associated potential risk of hypothyroidism. Nutrition Reviews 74, 248-258.

Gmelin, R., Kjær, A., Schuster, A., 1970. Glucosinolates in seeds of Sibara virginica (L.) Rollins: Two new glucosinolates. Acta Chem. Scand. 24, 3031-3037.

Gnas, Y., Glorius, F., 2006. Chiral auxiliaries - principles and recent applications. Synthesis 12, 1899-1930.

Greer, M. A., 1956. Isolation from rutabaga seed of progoitrin, the precursor of the naturally occuring antithyroid compound, goitrin (L-5-vinyl-2-thiooxazolidone). J. Am. Chem. Soc. 78, 1260-1261.

Haack M., Löwinger M., Lippmann D., Kipp A., Pagnotta E., lori R., Monien B.H., Glatt H., Brauer M.N., Wessjohann L.A., Brigelius-Flohé R., 2010. Breakdown products of neoglucobrassicin inhibit activation of Nrf2 target genes mediated by myrosinase-derived glucoraphanin hydrolysis products. Biol. Chem. 391, 1281-1293.

Halkier, B.A., Gershenzon, J., 2006. Biology and biochemistry of glucosinolates. Ann. Rev Plant Biol. 57, 303-333.

Hanschen, F.S., lamy, E., Schreiner, M., Rohn, S., 2014. Reactivity and stability of glucosinolates and their breakdown products in foods. Angew. Chem. Int. Ed. 53, 2-23.

Hanschen, F.S., Scheiner, M., 2017. Isothiocyanates, nitriles, and epithionitriles from glucosinolates are affected by genotype and developmental stage in Brassica oleraceae varieties. Front. Plant Sci. 8, 1095. 
Hanschen, F.S., Kaufmann, M., Kupfe, F., Hackl, T., Kroh, L.W., Rohn, S., Schreiner, M., 2018. Brassica vegetables as sources of epithionitriles: novel secondary products formed during cooking. Food Chem. 245, 564-569.

Hansen, B.G., Kerwin, R.E., Ober, J.A., Lambrix, V.M., Mitchell.Olds, T., Gershenzon, J., Halkier, B.A., Kliebenstein, D.J., 2008. A novel 2-oxoacid-dependent dioxygenase involved in the formation of goiterogenic 2-hydroxybut-3-enyl glucosinolate and generalist insect resistance in Arabidopsis. Plant Physiol. 148, 2096-2108.

Heimes, C., Agerbirk, N., Sørensen, H, van Mölken, T., Hauser, T. P., 2016. Ecotopic differentiation of two sympatric chemotypes of Barbarea vulgaris (Brassicaceae) with different biotic resistances. Plant Ecol. 217, 1055-1068.

Jones, D.T., Taylor, W.R., Thornton, J.M., 1992. The rapid generation of mutation data matrices from protein sequences. Bioinformatics 8, 275-282.

Khakimov, B., Tseng, L.H., Godejohann, M., Bak, S., Engelsen, S.B., 2016. Screening for triterpenoid saponins in plants using hyphenated analytical platforms. Molecules 21: 1614.

Kjær, A., Gmelin, R., Jensen, R. B., 1956. isoThiocyanates XVI. Glucoconringiin, the natural precursor of 5,5dimethyl-2-oxazolidinethione. Acta Chem. Scand. 10, 432-438.

Kjær, A., Gmelin, R., 1957. isoThiocyanates XXVIII. A new isothiocyanate glucoside (glucobarbarin) furnishing (-)-5-phenyl-2-oxazolidinethione upon enzymic hydrolysis. Acta Chem. Scand. 11, 906-907

Kjær, A., Gmelin, R., 1958. isoThiocyanates XXXIII. An isothiocyanate glucoside (glucobarbarin) of Reseda luteola L. Acta Chem. Scand. 12, 1693-1694.

Klein, A.P., Sattely, E.S., 2017. Biosynthesis of cabbage phytoalexins from indole glucosinolates. Proc. Natl. Acad. Sci. U.S.A. 114, 1910-1915.

Laatikainen, R., Niemitz, M., Weber, U., Sundelin, J., Hassinen, T., Vepsäläinen, J., 1996. General strategies for total-line-shape type spectral analysis of NMR spectra using integral transform integrator. J. Magn. Reson. Series A 120, 1-10.

Lazzeri L., Leoni O., Conte L.S., Palmieri S., 1994. Some technological characteristics and potential uses of Crambe abyssinica products. Ind. Crops and Prod., 3, 103-112.

Lazzeri, L., Malaguti, L., Cinti, S., Ugolini, L., De Nicola, G. R., Bagatta, M., Matteo, R., Casadei, N., Patalano, G., D'Avino, L., 2013. The Brassicaceae biofumigation system for plant cultivation and defence. An Italian twenty-year experience of study and application. Acta Hortic. 1005, 375-382.

Leoni, O, Bernardi, R., Gueyrard, D., Rollin, P., Palmieri, S., 1999. Chemo-enzymatic preparation from renewable resources of enantiopure 1,3-oxazolidine-2-thiones. Tetrahedron: Asymmetry 10, 4775-4780.

Liu, T., Zhang, X., Yang, H., Agerbirk, N., Qiu, Y., Wang, H., Shen, D., Song, J., Li, X., 2016. Aromatic glucosinolate biosynthesis pathway in Barbarea vulgaris and its response to Plutella xylostella infestation. Front. Plant Sci. 7, 83. 
Lutfullin, K.L., Tadzhibaev, M.M., Abdullaev, U.A., Malikov, V.M., Yunusov, S.Y., 1976. Alkaloids of Reseda luteola. Khimiya Prirodnykh Soedinenii 5, 625-630 (In Russian).

Malinowski, F.G., Thomsen, M.-L., Nintemann, S.J., Jagd, L.M., Bourgine, B., Burow, M., Kliebenstein, D.J., 2017. An evolutionary young defense metabolite influences the root growth of plants via the ancient TOR signaling pathway. ELIFE 6, e29353.

Matich, A.J., McKenzie, M.J., Lill, R.E., Brummell, D.A., McGhie, T.K., Chen, R. K.-Y., Rowan, D.D., 2012. Selenoglucosinolates and their metabolites produced in Brassica spp. fertilized with sodium selenate. Phytochemistry $75,140-152$.

Maruyama-Nakashita, A., 2017. Metabolic changes sustain the plant life in low-sulfur environments. Curr. Opin. Plant Biol. 39, 144-151.

Montaut, S., Zhang, W.-D., Nuzillard, J.-M., De Nicola, G.R., Rollin, P., 2015. Glucosinolate diversity in Bretschneidera sinensis of Chinese origin. J. Nat. Prod. 78, 2001-2006.

Montaut, S., Bleeker, R.S., 2010. Isolation and structure elucidation of 5'-O- $\beta$-Dglucopyranosyldihydroascorbigen from Cardamine diphylla rhizome. Carbohydrate Res. 345, 1968-1970.

Moreno-Mañas, M., Padros, I., 1993. Preparation of oxazolidin-2-ones by oxidation of oxazolidine-2thiones. A proton magnetic resonance structural study. J. Heterocyclic Chem. 1993, 30, 1235-1239

Nakano, R.T., Pislewska-Bednarek, M., Yamada, K., Edger, P.P., Miyahara, M., Kondo, M., Bottcher, C., Mori, M., Nishimura, M., Schulze-Lefert, P., Hara-Nishimura, I., Bednarek, P., 2017. PYK10 myrosinase revelas a functional coordination between endoplasmic reticulum bodies and glucosinolates in Arabidopsis thaliana. Plant J. 89, 204-220.

Nintemann, S.J., Hunziker, P., Andersen, T.G., Schulz, A., Burow, M., Halkier, B.A., 2018. Localization of the glucosinolate biosynthetic enzymes reveals distinct spatial patterns for the biosynthesis of indole and aliphatic glucosinolates. Physiol. Plant. In press

Nour-Eldin, H.H., Madsen, S.R., Engelen, S., Jørgensen, M.E., Olsen, C.E., Andersen, J.S., Seynnaeve, D., Verhoye, T., Fulawka, R., Denolf, P., Halkier, B.A., 2017. Reduction of antinutritional glucosinolates in Brassica oilseeds by mutation of genes encoding transporters. Nat. Biotechnol. 35, 377-382.

Olsen, C.E., Huang, X.-C., Hansen, C.I.C., Cipollini, D., Ørgaard, M., Matthes, A., Geu-Flores, F., Koch, M.A., Agerbirk, N., 2016. Glucosinolate diversity within a phylogenetic framework of the tribe Cardamineae (Brassicaceae) unravelled with HPLC-MS/MS and NMR-based analytical distinction of 70 desulfoglucosinolates. Phytochemistry 132, 33-56.

Olsen, O., Sørensen, H., 1979. Isolation of glucosinolates and the identification of $o-(\alpha-L-$ rhamnopyranosyloxy)benzylglucosinolate from Reseda odorata. Phytochemistry 18, 1547-1552.

Pagnotta, E., Agerbirk, N., Olsen, C.E., Ugolini, L., Cinti, S., Lazzeri, L., 2017. Hydroxyl and methoxyl derivatives of benzylglucosinolate in Lepidium densiflorum with hydrolysis to isothiocyanates and non- 
isothiocyanate products: substitution governs product type and mass spectral fragmentation. J. Agric. Food Chem. 65, 3167-3178.

Pastorczyk, M., Bednarek, P., 2016. The function of glucosinolates and related metabolites in innate immunity. Adv. Bot. Res. 80, 171-198.

Pedras, M.S.C, To, Q.H., 2014. The first non-indolyl cruciferous phytoalexins: nasturlexins and tridentatols, a striking convergent evolution of defenses in terrestrial plants and marine animals? Phytochemistry 113, 5763.

Pedras, M.S.C., Alavi, M., To, H., 2015. Expanding the nasturlexin family: nasturlexins $C$ and $D$ and their sulfoxides are phytoalexins of the crucifers Barbarea vulgaris and B. verna. Phytochemistry 118, 131-138.

Pedras, M.S.C., To, Q.H., Schatte, G., 2016. Divergent reactivity of an indole glucosinolate yields Lossen and Neber rearrangement products: the phytoalexin rapalexin $A$ or a unique $\beta$-D-glucopyranose fused heterocycle. Chem. Commun. 52, 2505-2508.

Pfalz, M., Mukhaimar, M., Perreau, F., Kirk, J., Hansen, C.I.C., Olsen, C.E., Agerbirk, N., Kroymann, J., 2016. Methyl transfer in glucosinolate biosynthesis mediated by indole glucosinolate $O$-methyltransferase 5 . Plant Physiol. 172, 2190-2203.

Pislewska-Bednarek, M., Nakano, R.T., Hiruma, K., Pastorczyk, M., Sanchez-Vallet, A., Singkaravanit-Ogawa, S., Ciesiolka, D., Takano, Y., Molina, A., Schulze-Lefert, P., Bednarek, P., 2018. Glutathione transferase U13 functions in pathogen-triggered glucosinolate metabolism. Plant Phys. 176, 538-551.

Radulovic, N.S., Todorovska, M.M., Zlatkovic, D.B., Stojanovic, N.M., Randjelovic, P.J., 2017. Two goitrogenic 1,3-oxazolidine-2-thione derivatives from Brassicales taxa: challenging identification, occurrence and immunomodulatory effects. Food Chem. Toxicol. 110, 94-108.

Sheng, S.-R., Luo, H.-R., Huang, Z.-Z., Sun, W.-K., Liu, X.-L., 2017. Facile one-pot synthesis of oxazolidin-2ones from phenyl 2-hydroxyalkyl selenides. Synth. Comm. 37, 2693-2699.

Stevens, J.F., Reed, R.L., Alber, S., Pritchett, L., Machado, S., 2009. Herbicidal activity of glucosinolate degradation products in fermented meadowfoam (Limnanthes alba) seed meal. J. Agric. Food Chem. 57, 1821-1826.

Tamura, K., Stecher, G., Peterson, D., Filipski, A., Kumar, S., 2013. MEGA6: molecular evolutionary genetics analysis version $6.0 \mathrm{Mol}$. Biol. Evol. 30, 2725-2729.

Wei, X., Zhang, X., Shen, D., Wang, H., Wu, Q., Lu, P., Qiu, Y., Song, J., Zhang, Y., Li, X., 2013. Transcriptome analysis of Barbarea vulgaris infested with diamondback moth (Plutella xylostella) larvae. PLoS one 8 , e64481.

Wittstock, U., Kurzbach, E., Herfurth, A.-M., Stauber, E.J., 2017. Glucosinolate breakdown. Adv. Bot. Res. 80 125-169.

Yang, T., Nagy, I., Mancinotti, D., Otterbach, S., Andersen, T.B., Motawia, M.S., Asp, T., Geu-Flores, F. (2017) Transcript profiling of a bitter variety of narrow-leafed lupin to discover alkaloid biosynthetic genes. J. Exp. Bot. 68, 5527-5537. 
Zhang, X., Liu, T., Wei, X., Qiu, Y., Song, J., Wang, H., Shen, D., Agerbirk, N., Li, X., 2015. Expression patterns, molecular markers and genetic diversity of insect-susceptible and resistant Barbarea genotypes by comparative transcriptome analysis. BMC genomics 16, 486. 
Figure 1. Three heterocyclic ring systems found in Brassicales metabolites (1,3-oxazolidine-2-thione (OAT), 1,3-thiazolidin-2-one (TAO), oxazolidin-2-one (OAO), and their parent heterocyclic frames. Substituted OAT and TAO are known glucosinolate degradation products. In this paper, biochemical conversion of 5substituted OATs into 5 -substituted OAOs is suggested.

Figure 2. Reactions of glucobarbarin investigated in this paper. A. Biochemical conversion of glucobarbarin into barbarin via an unstable isothiocyanate, and the further conversion to resedine catalyzed by a heatsensitive factor as demonstrated in this paper. The heat-sensitive factor is suggested to be a plant enzyme, for which we suggest the common name oxazolidinethionase (OATase). Turnover in intact plants is likely to involve a different thioglucosidase than myrosinase (MYR). B. An alternative outcome of MYR-catalyzed hydrolysis, in the presence of ferrous ion. C. Hypothetic, non-enzymatic conversion of glucobarbarin to a thioamide. This reaction had been suggested in the literature but was not confirmed here.

Figure 3. Chromatograms (ion trap HPLC-MS) of glucobarbarin degradation products formed in the presence of myrosinase (MYR) and absence (A) or presence (B) of $2.5 \mathrm{mM} \mathrm{FeCl}_{2}$. Extracted ion chromatograms (EIC) are shown, measuring relevant $m / z$ values (+/- 0.5 ) as follows: 2, 202, 180, 146, 120; 4, 170, 148, 130; hypothetic "5", $204[\mathrm{M}+\mathrm{Na}]^{+}, 182[\mathrm{M}+\mathrm{H}]^{+}, 164\left[\mathrm{M}-\mathrm{H}_{2} \mathrm{O}+\mathrm{H}\right]^{+}$. Scales for 4 and hypothetic " 5 " are identical, while the scale for $\mathbf{2}$ is ten-fold as condensed to account for observed higher sensitivity for $\mathbf{2}$. Unidentified trace peaks $\mathbf{x} \mathbf{1}(\mathrm{m} / \mathrm{z} \mathrm{181})$ and $\mathbf{x} \mathbf{2}(\mathrm{m} / \mathrm{z} 164$ but not 204 or 182$)$ did not agree with expected MS of hypothetic " 5 " or resedine (3).

Figure 4. Ion trap mass spectra of the nitrile $4(A)$ derived from glucobarbarin as well as two related model compounds, 4-hydroxyphenylacetonitrile (6) (B) and 2-hydroxy-(4-hydroxyphenyl)acetonitrile (7) (C), for comparison of MS2 fragmentation.

Figure 5. Major products of ferrous ion-catalyzed degradation of glucobarbarin (1). A, reaction scheme; B, HPLC of products with UV detection at $210 \mathrm{~nm}$; C, ion trap MS and MS2 spectra of the tentatively identified amide $\mathbf{8}$, isolated from the HPLC-separation in B.

Figure 6. Detection of barbarin (2) and resedine (3) as products formed during autolysis of Barbarea vulgaris and Reseda luteola. A, B: chromatograms showing the product profile at various time points after autolysis of $B$. vulgaris (A) or R. luteola (B). C, D: lon trap mass spectra of barbarin (C) and resedine (D).

Figure 7. Time course of formation of glucobarbarin products at two different experimental designs, either autolysis in crushed tissue left undiluted (A), or with addition of buffer at $0.3 \mathrm{~h}$ in order to test heat sensitivity of the hypothesized enzyme (B). A. Time course of formation of resedine (2) relative to the sum of resedine and barbarin (3) in homogenized Barbarea vulgaris leaves or siliques harvested in May or June as indicated. B. Time course of formation of barbarin, resedine and the total of these, in autolyzed foliage added buffer at $0.3 \mathrm{~h}$ (arrow) and subjected to brief heating at either $0.3 \mathrm{~h}, 6.3 \mathrm{~h}$ or $24.3 \mathrm{~h}$, followed by continued incubation at room temperature and hot extraction at $25 \mathrm{~h}$. Autolysis time (x-axis) was defined as the time span until the brief heating.

Figure 8. Conversion of spiked 5-ethyl-5-methylOAT (9) into 5-ethyl-5-methylOAO (10) catalyzed by a heatsensitive catalyst named oxazolidinethionase (OATase) in Barbarea vulgaris leaf homogenates (A) and ion trap MS/MS (B) confirmation of the identity of the product $\mathbf{1 0}$ (from chromatogram in Figure $9 \mathrm{E}$ ). 
Figure 9. Evidence for conversion of spiked (S)-5-ethyl-5-methylOAT (9) into 5-ethyl-5-methylOAO (10) by a heat-sensitive catalyst in a B. vulgaris leaf homogenate. A-D, Total ion chromatograms; $E-H$, extracted ion chromatograms for specific detection of the $\mathrm{OAO}$ product $10 . \mathrm{A}+\mathrm{E}$, extract of native homogenate after incubation ( $2 \mathrm{~h}$ ) with spike of 9 dissolved in water; $B+F$, control extract of homogenate spiked with water; $C+G$, control similar to $A+E$ but homogenate heated in test tube surrounded by boiling water for 4 min before spike; $\mathrm{D}+\mathrm{H}$, control consisting of the same spike as in $\mathrm{A}$ and $\mathrm{C}$ but incubated in acetate buffer $(\mathrm{pH} 5$, $2 \mathrm{~h}$ ) in parallel.

Figure 10. Molecular phylogenetic analysis (maximum likelihood) of candidate genes for the initial step of glucosinolate turnover in Barbarea vulgaris compared to homologs from Arabidopsis thaliana and Brassica rapa. In gene names, the three species are indicated by prefixes $\mathrm{Bv}$, At and $\mathrm{Br}$, respectively. Transcriptomes of two ecotypes of $B$. vulgaris (P-type and G-type) were used, and an asterisk $\left({ }^{*}\right)$ denote $B$. vulgaris sequences also found in both P-type and G-type transcriptomes. The bar represents number of substitutions per site. Only bootstrap values above 70 are shown in the tree.

Figure 11. Synthetic conversion of an oxazolidine-2-thione (barbarin, 2) into an oxazolidin-2-one (resedine, 3) and an amino-alcohol side-product (13). 
Table 1. Relative levels (mole \%, mean (SD)) of glucobarbarin degradation products in selected species and organs. Flowering $2^{\text {nd }}$ year $B$. vulgaris plants were tested repeatedly during three months, while other species and seeds/seedlings were tested at one time point only. Experimental variation of the conditions included no autolysis (direct, hot extraction), artificial addition of $\mathrm{FeSO}_{4}$, and siliques compared to leaves. Levels of the nitrile product (4) represent maximum estimates based on trace peaks that were in no case confirmed by a clear MS2 spectrum. This uncertainty was due to the detector sensitivity for the nitrile being much lower than for $\mathbf{2}$ and 3. Estimates of standard deviation in case of $\mathrm{N}=2$ are explained in Section 3.6.

\begin{tabular}{|c|c|c|c|c|}
\hline Conditions $^{\mathrm{a}}$ & 2 & 3 & $(4)$ & $\mathrm{N}$ \\
\hline \multicolumn{5}{|c|}{ Barbarea vulgaris (G-type) } \\
\hline Leaves, April, $1 \mathrm{~h}$ & $78(2)$ & $20(4)$ & $1(2)$ & 3 \\
\hline \multicolumn{5}{|l|}{ Leaves, May } \\
\hline$-0.5 \mathrm{~h}$ autolysis & $92(1)$ & $8(1)$ & n.d. & 2 \\
\hline -no autolysis control & $(100)^{b}$ & n.d. & n.d. & 1 \\
\hline \multicolumn{5}{|l|}{ Leaves, June, $1 \mathrm{~h}^{\mathrm{c}}$} \\
\hline -with added $\mathrm{FeSO}_{4}$ & $90(5)$ & $7(1)$ & $3(4)$ & 2 \\
\hline - no $\mathrm{FeSO}_{4}$ control & $89(2)$ & $11(1)$ & $0.5(0.7)$ & 2 \\
\hline \multicolumn{5}{|l|}{ Siliques, June } \\
\hline$-0.5 \mathrm{~h}$ autolysis & $94(3)$ & $6(3)$ & n.d. & 2 \\
\hline - no autolysis control & $(100)^{b}$ & n.d. & n.d. & 1 \\
\hline Seeds, $1 \mathrm{~h}, \mathrm{H}_{2} \mathrm{O}^{\mathrm{d}}$ & 97 & 3 & n.d. & 1 \\
\hline Seedlings, $1 \mathrm{~h}$ & 74 & 8 & 18 & $1^{\mathrm{e}}$ \\
\hline
\end{tabular}

\begin{tabular}{|c|c|c|c|c|}
\hline \multicolumn{5}{|l|}{ Reseda luteola ${ }^{f}$} \\
\hline \multicolumn{5}{|c|}{ Leaves $(N=2+2)$, shoot axes $(N=1+1)$, June } \\
\hline$-1 \mathrm{~h}$ autolysis & $88(2)$ & $11(2)$ & $0.6(0.6)$ & \\
\hline -no autolysis control & $(100)^{b}$ & n.d. & tr. & \\
\hline Seeds, $1 \mathrm{~h}, \mathrm{H}_{2} \mathrm{O}^{\mathrm{d}}$ & $99(0.3)$ & $0.6(0.3)$ & n.d. & \\
\hline
\end{tabular}

Reseda odorata ${ }^{g}$

Seeds, $1 \mathrm{~h}, \mathrm{H}_{2} \mathrm{O}^{\mathrm{d}}$

n.d. $\quad$ n.d.

n.d. $\quad 1$

a Species, organ, sampling month, duration of autolysis, other experimental conditions

${ }^{\mathrm{b}}$ Around $5 \%$ of absolute level after autolysis, probably reflecting un-intended, limited tissue damage during sampling.

${ }^{\mathrm{c}}$ Tissue homogenized (1:1 w/w) with $100 \mathrm{mM}$ acetic acid- $\mathrm{NaOH} \mathrm{pH} \mathrm{5,} 10 \mathrm{mM}$ ascorbic acid with or without $5 \mathrm{mM} \mathrm{FeSO}_{4}$ added on the day of the experiment (equivalent to $2.5 \mathrm{mM} \mathrm{FeSO}_{4}$ in resulting homogenate).

d $0.1 \mathrm{~g}$ seed $+0.3 \mathrm{ml} \mathrm{H} \mathrm{H}_{2} \mathrm{O}$.

${ }^{\text {e }}$ Extract of 25 pooled young, entire seedlings ( $2 \mathrm{~cm}$ long).

${ }^{\mathrm{f}}$ Detected glucosinolates in $R$. luteola leaves and seeds were glucobarbarin (dominant) and some phenethylglucosinolate, indol-3-ylmethylglucosinolate and epiglucobarbarin (minor).

${ }^{\mathrm{g}}$ Glucosinolates in $R$. odorata did not include glucobarbarin. The main glucosinolate, after desulfation, showed $t_{R}$ almost as indol-3-ylmethylglucosinolate and an $\mathrm{m} / z$ value of $514[\mathrm{M}+\mathrm{Na}]^{+}$and $492[\mathrm{M}+\mathrm{H}]^{+}$, and 
fragments at $m / z 330$ and 184. The latter fragments were also seen in MS2 of the proton adduct, as expected for loss of anhydroglucose $\left(\mathrm{m} / \mathrm{z} 330,[\mathrm{M}-162+\mathrm{H}]^{+}\right)$and further loss of anhydrorhamnose $(\mathrm{m} / \mathrm{z} 184$, $\left.[\mathrm{M}-162-146+\mathrm{H}]^{+}\right)$. All of this would be in accordance with dominance of $o$-rhamnosyloxybenzylglucosinolate as expected for the species (Olsen and Sørensen, 1979). 
Supplementary figure 1 . UV spectra of resedine and barbarin.

Supplementary figure 2. HPLC-DAD analyses of $B$. vulgaris autolysis extracts and isolation of resedine.

Supplementary figure 3. NMR spectra of resedine.

Supplementary figure 4. Resedine as an autolysis product in watercress, Nasturtium officinale.

Supplementary figure 5. Detection of the corresponding OAO after spiking B. vulgaris homogenates with 5vinylOAT (goitrin).

Supplementary figure 6. HPLC-UV chromatograms of extracts of spiked B. vulgaris autolysates, showing approximately equal levels of endogenous barbarin and the spiked OATs.

Supplementary figure 7. Synthesis of resedine and MS identification.

Supplementary figure 8. Synthesis of 5-ethyl-5-methylOAO and MS identification.

Supplementary figure 9. Synthesis of 5-vinyIOAT and MS identification. 
Figure 1

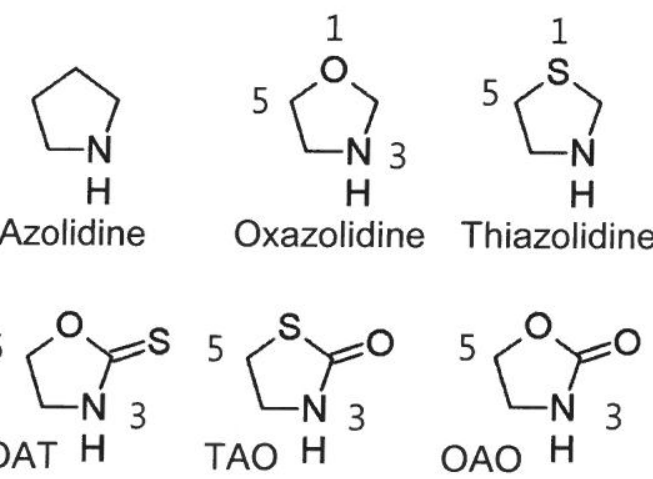


Figure 2

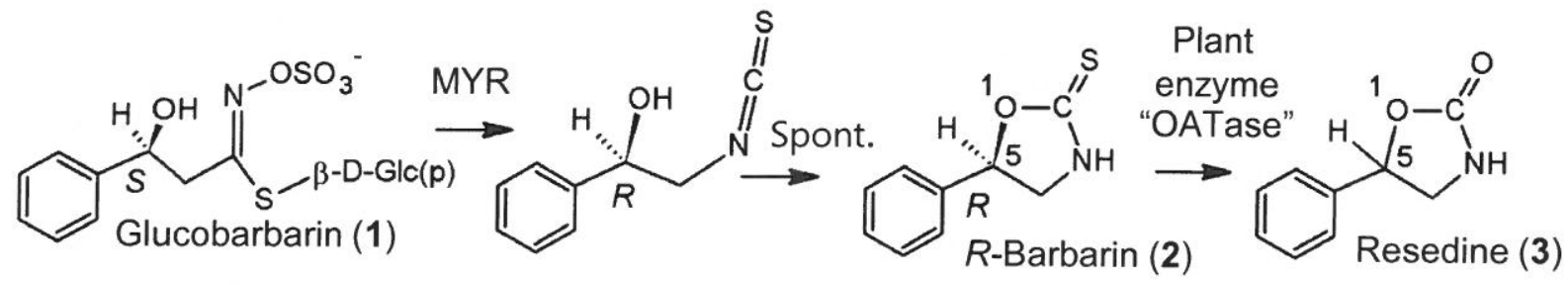


Figure 3
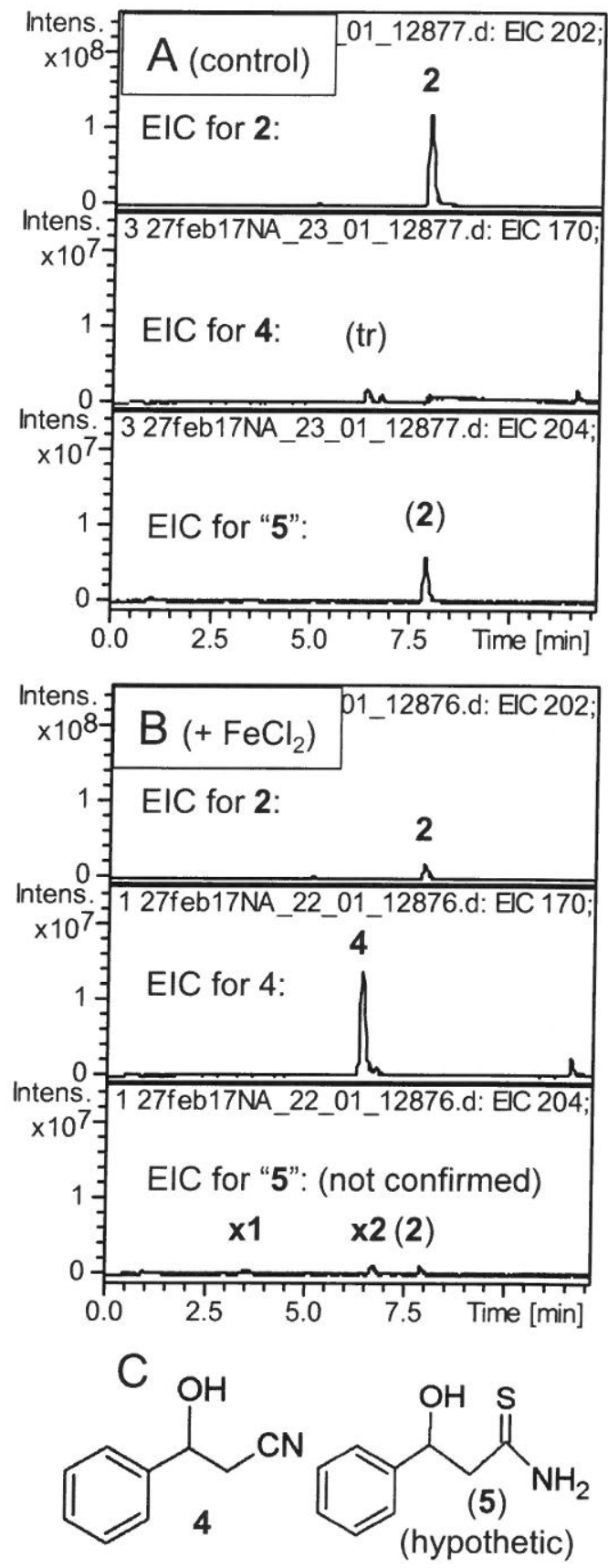
Figure 4
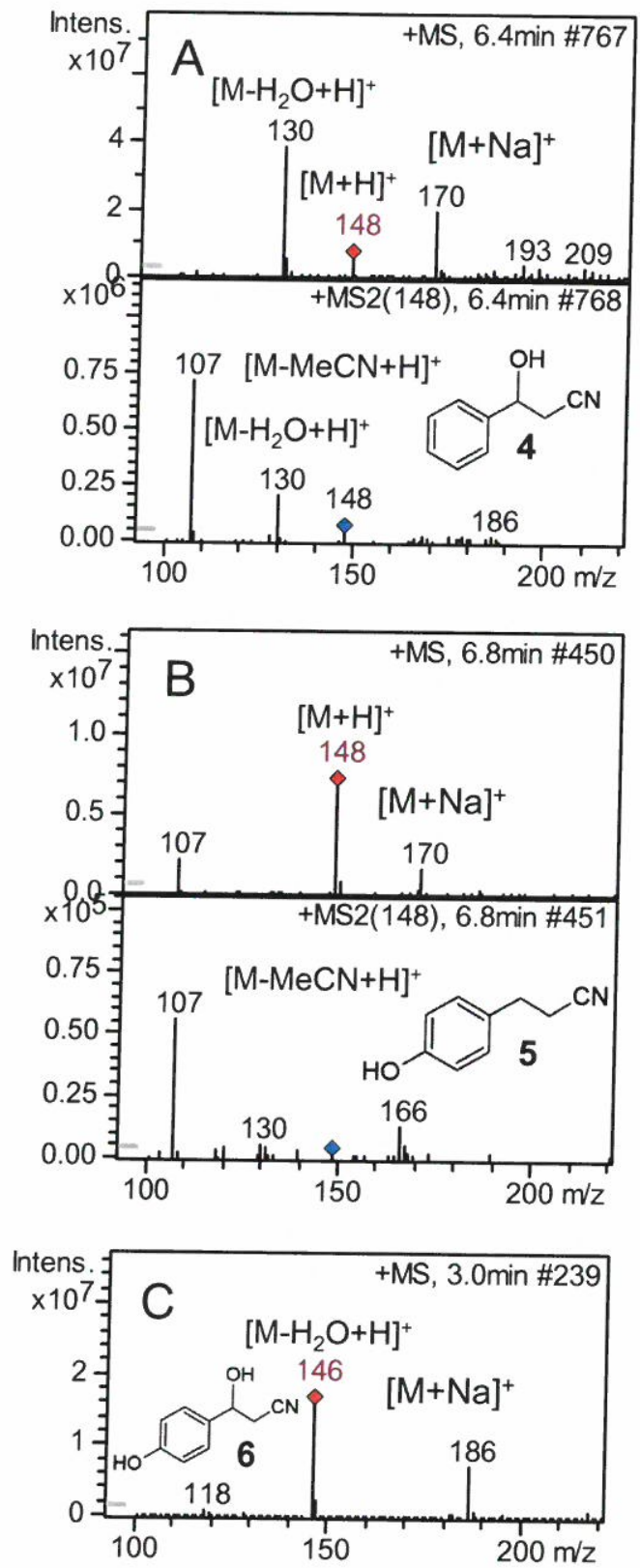


\section{Figure 5}

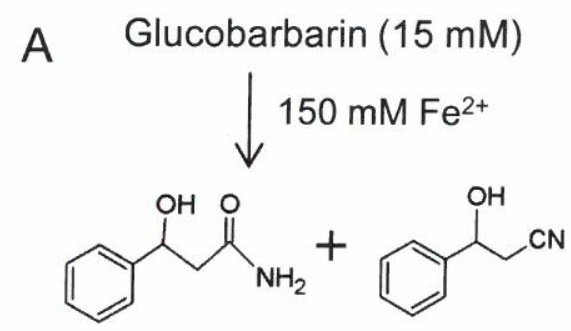

(Amide, 8) (Nitrile, 4)

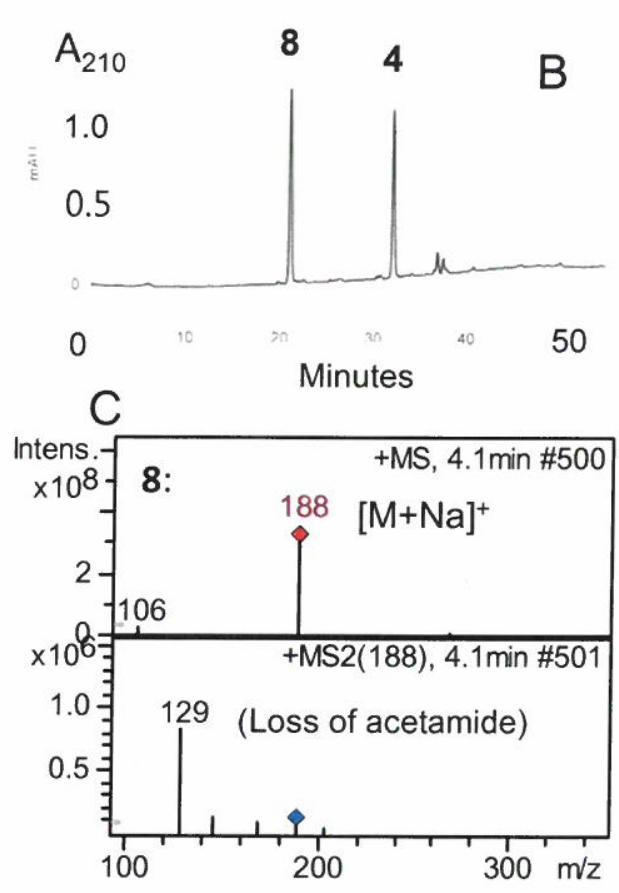


Figure 6
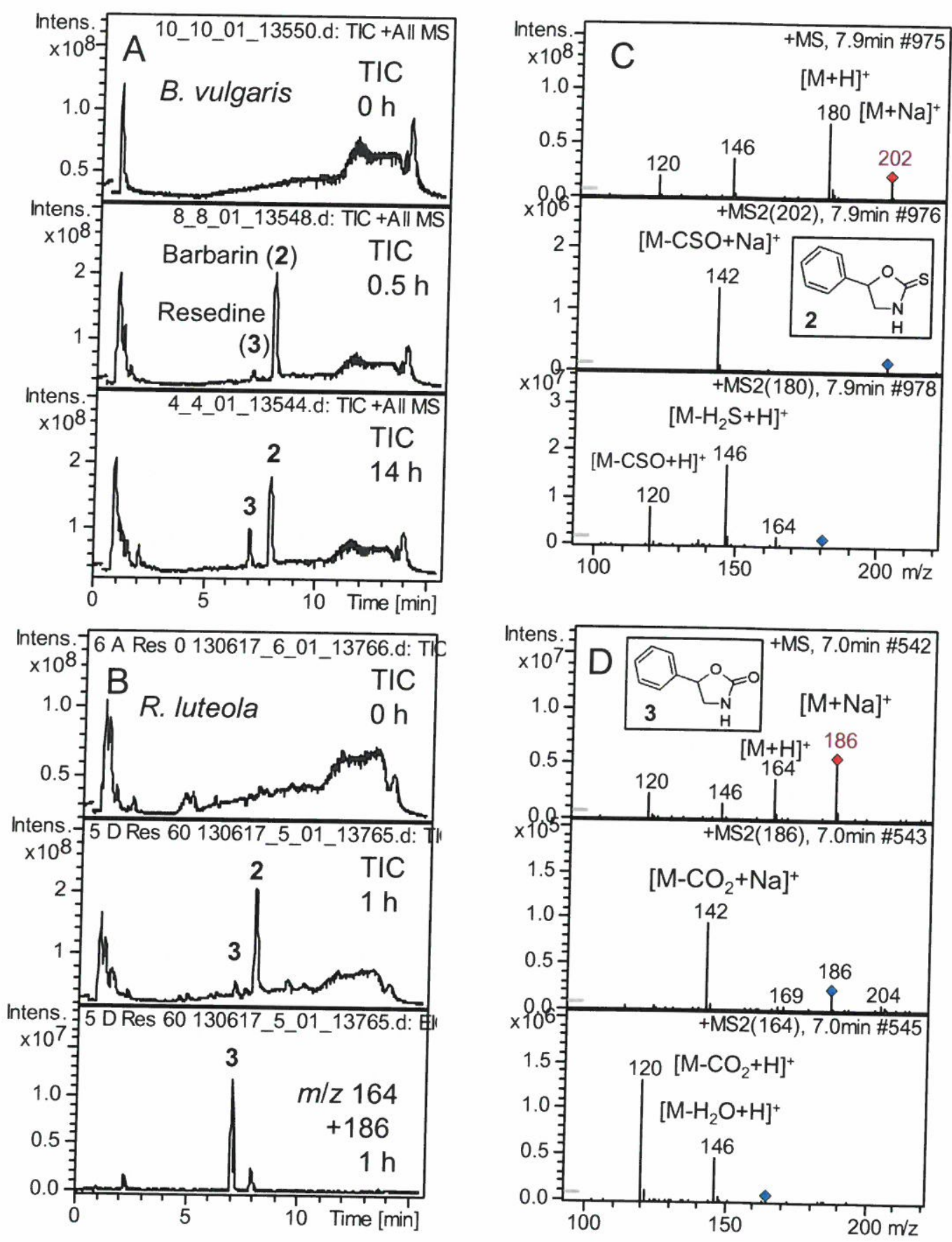
Figure 7

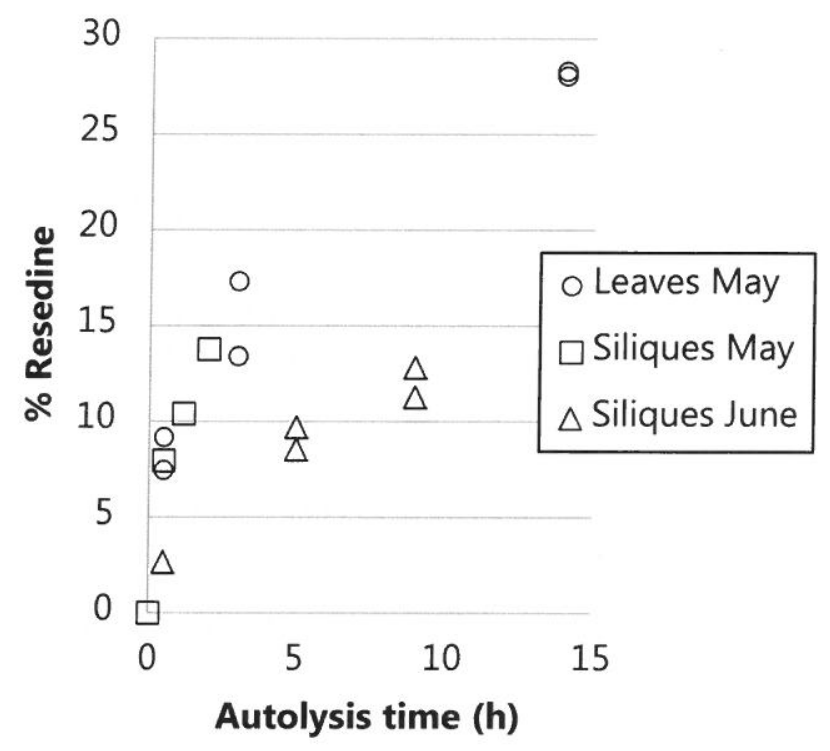


Figure 8 .

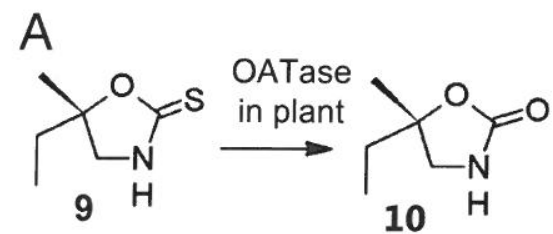

B

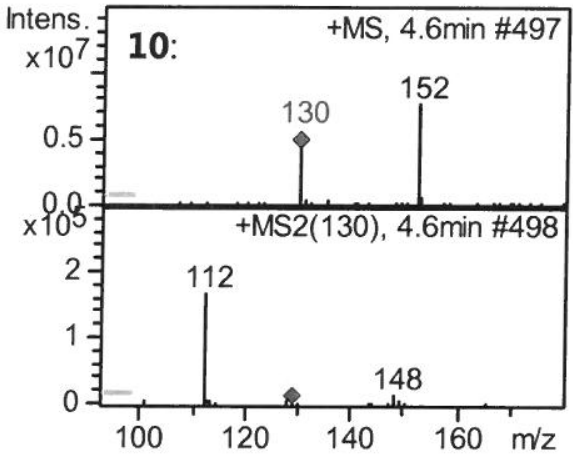


Figure 9

Total Ion Chromatogram

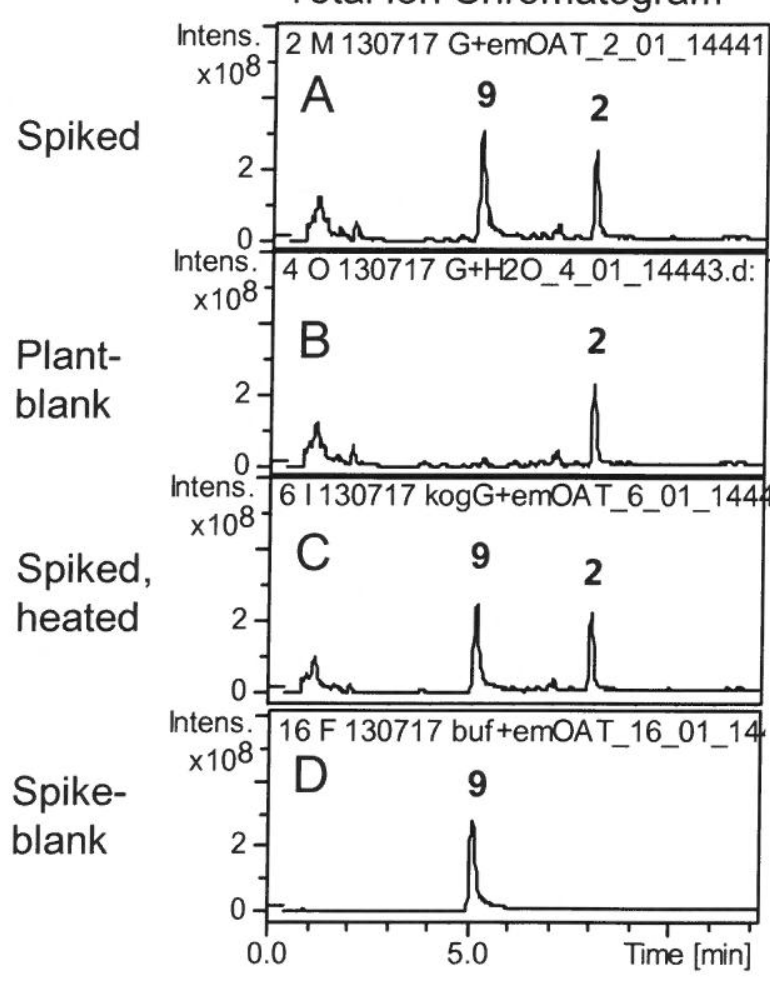

EIC of $\mathrm{m} / \mathrm{z} 130 \& 152$

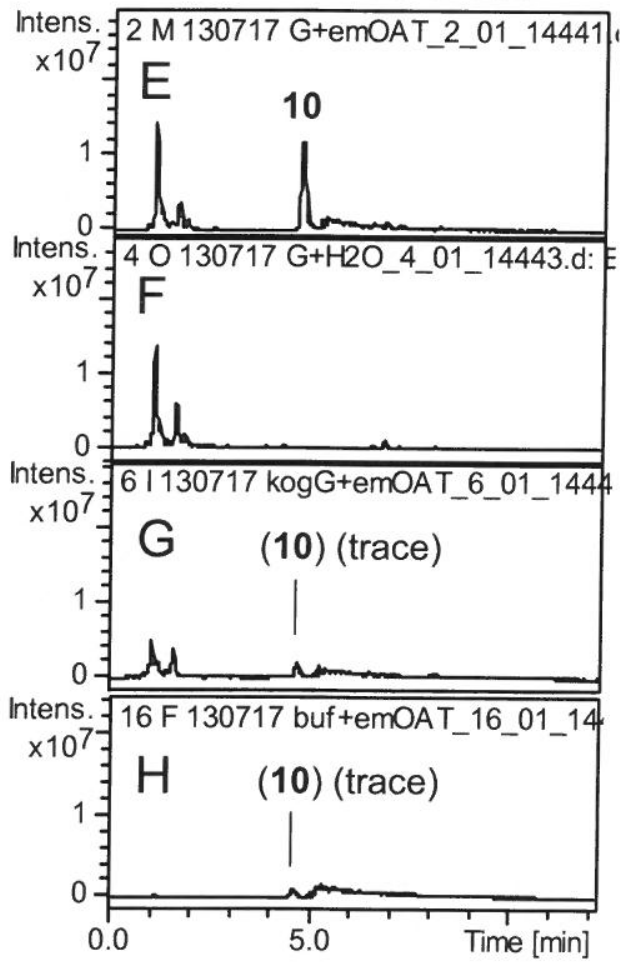


Figure 10

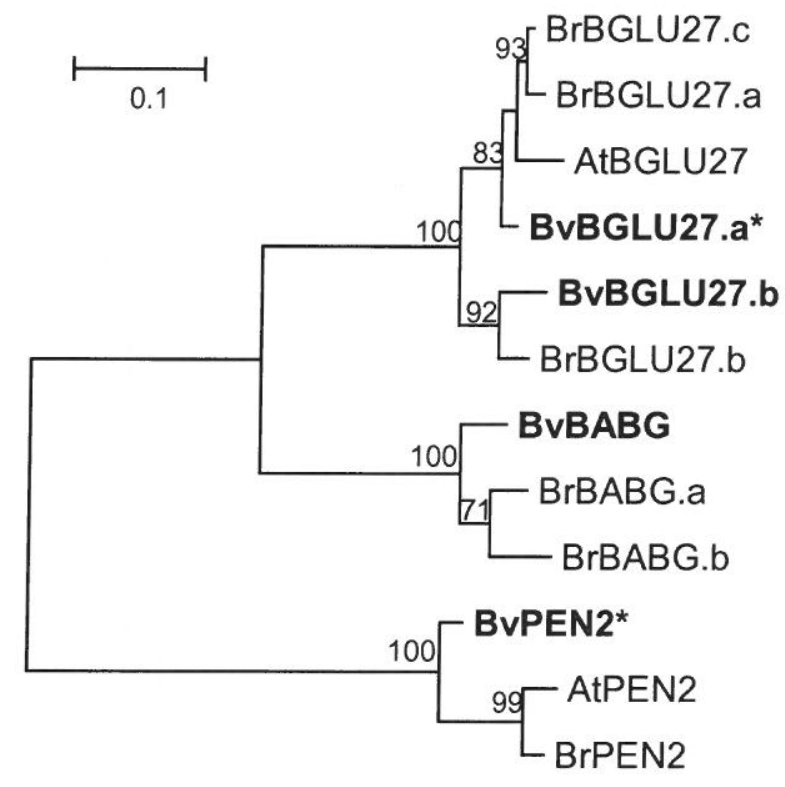




\section{Figure 11}

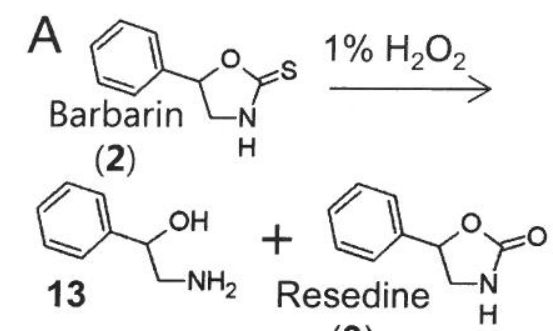

(3)

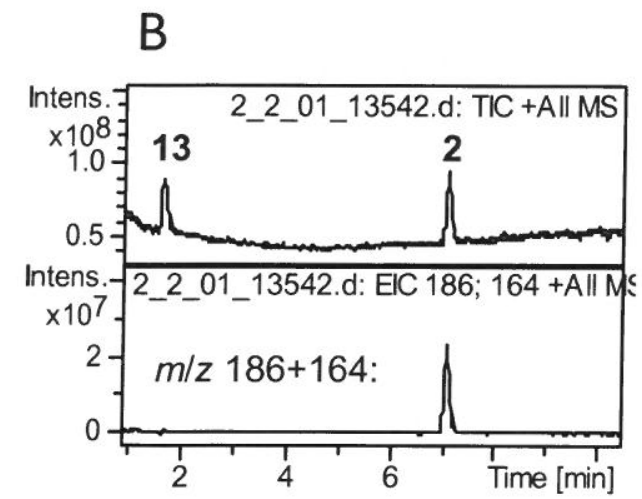


Supplementary material for:

Glucosinolate turnover to an oxazolidin-2-one, formed via the 2-thione, but no formation of thioamide (Phytochemistry xx, xx-xx (2018)

Authors: Niels Agerbirk, Annemarie Matthes, Pernille $\varnothing$. Erthmann, Luisa Ugolini, Susanna Cinti, Eleni Lazaridi, Jean-Marc Nuzillard, Caroline Müller, Søren Bak, Patrick Rollin; Luca Lazzeri

Supplementary Figure 1. HPLC-diode array UV spectra of resedine and barbarin from a B. vulgaris leaf extract. Solvent: aq. acetonitrile. In spectrum of resedine, the weak fine structure was centred at $256 \mathrm{~nm}$. The major band of barbarin was centred at $242 \mathrm{~nm}$.
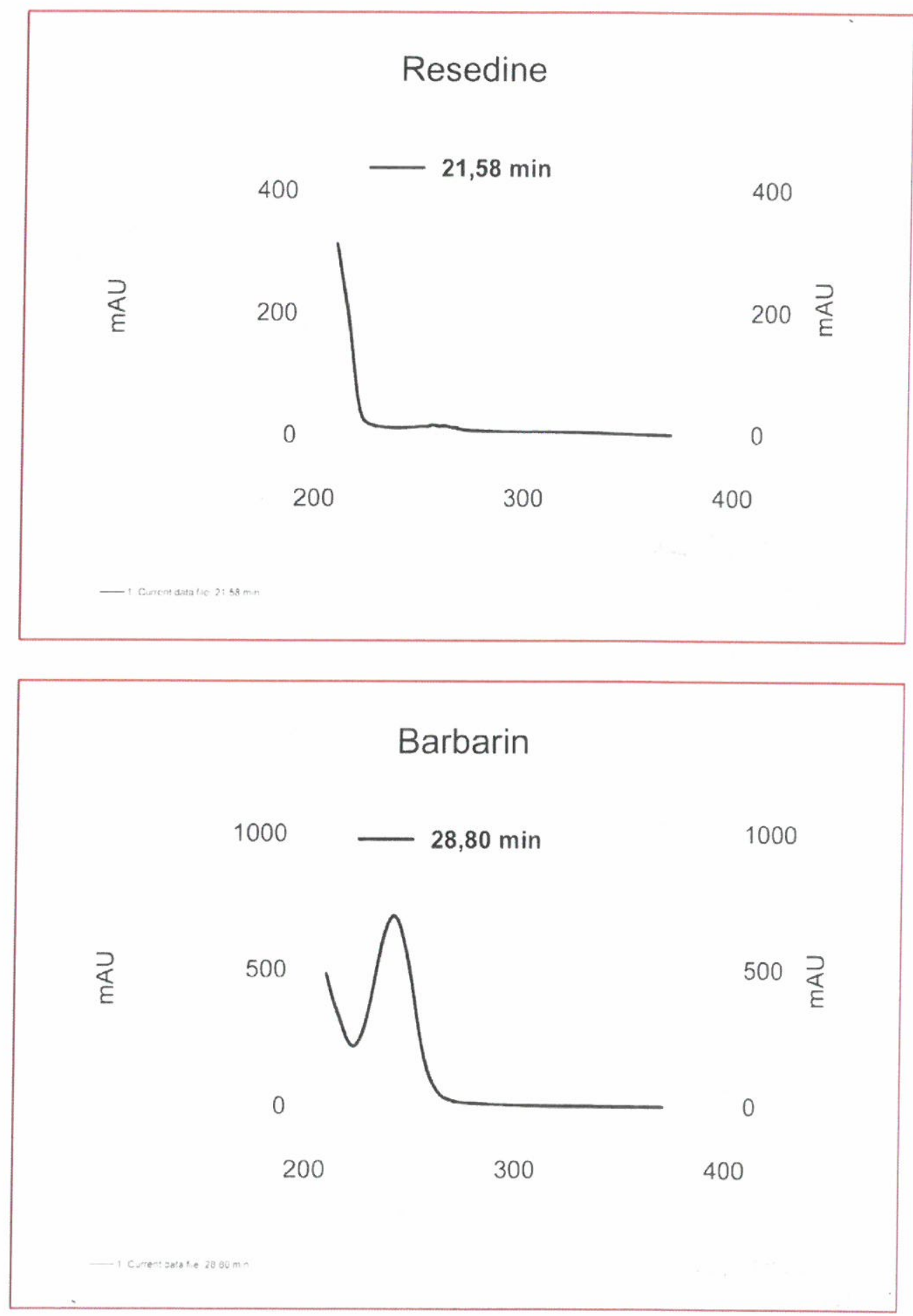


\section{Supplementary Figure 2. Isolation of resedine from $24 \mathrm{~h}$ Barbarea vulgaris foliage}

autolysis extracts. The extract (in $\mathrm{H}_{2} \mathrm{O}$ ) was loaded on a $\mathrm{C} 18$ cartridge. Eluates with $10 \%$ aq. $\mathrm{MeOH}$ and $20 \%$ aq. $\mathrm{MeOH}$ (A) were discarded after HPLC analysis showing lack of resedine. A second eluate with $70 \%$ aq. $\mathrm{MeOH}(\mathrm{B})$ contained resedine, barbarin and numerous other metabolites. Highly polar material was removed in the first eluate. Particles, saponins and unwanted sticky material stayed on the C18 cartridge. As resedine was reasonably well separated by HPLC of the mixture, the peak was collected from this separation without further optimization.

Material from 4 runs as illustrated was pooled, dried and used directly for the NMR analysis.

For the Shimadzu SPD-M10AVP DAD detector, the home made "prep. HPLC-NMR manual interphase" was made in 5 min with a $20 \mathrm{~cm}$ piece of HPLC tubing; an 8 second delay from UV detector to effluent was measured experimentally and taken into account during collection.

Full details of the isolation procedure are given in Section 3.12.
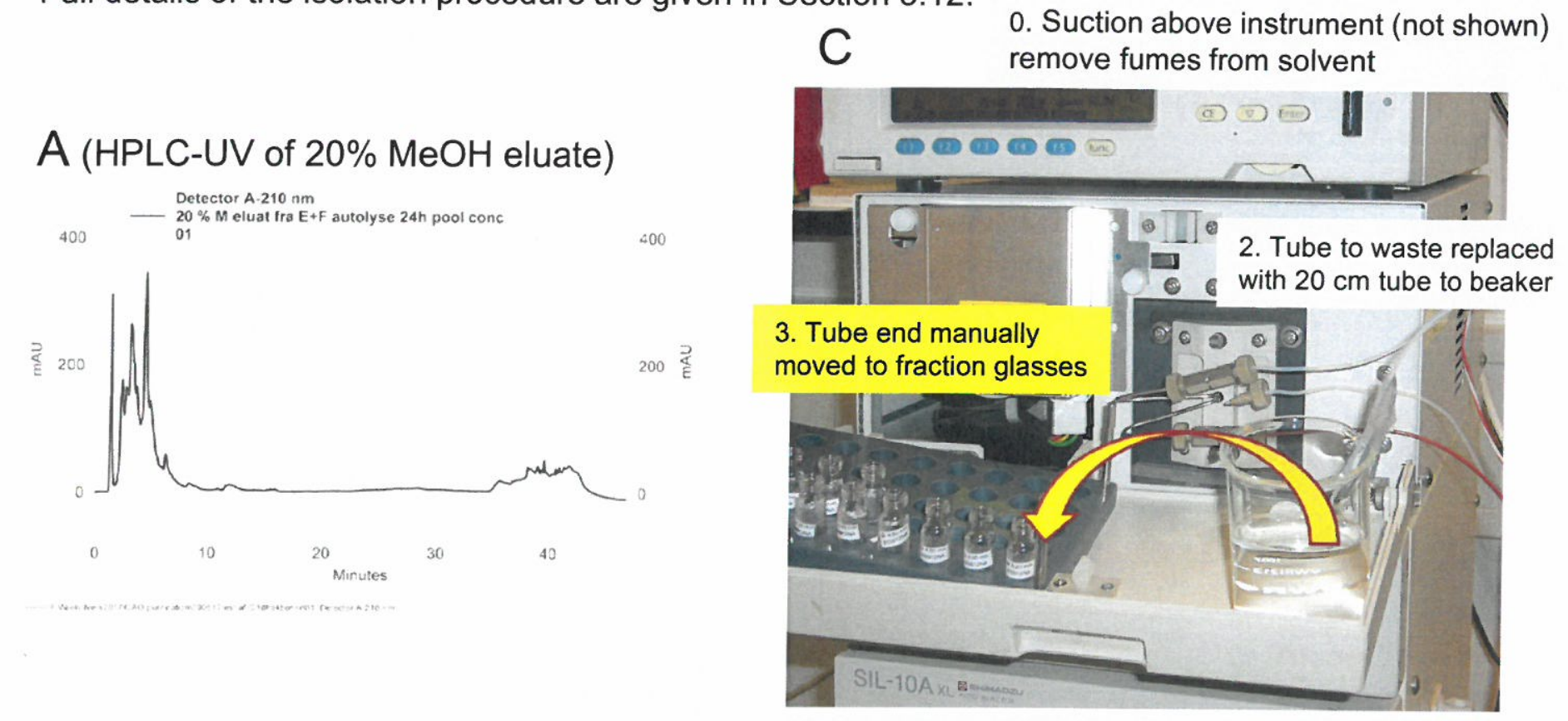

1. UV detector cabinet opened, used as mini-desk

\section{B (HPLC-UV of $70 \% \mathrm{MeOH}$ eluate)}

Detector A-210 nm

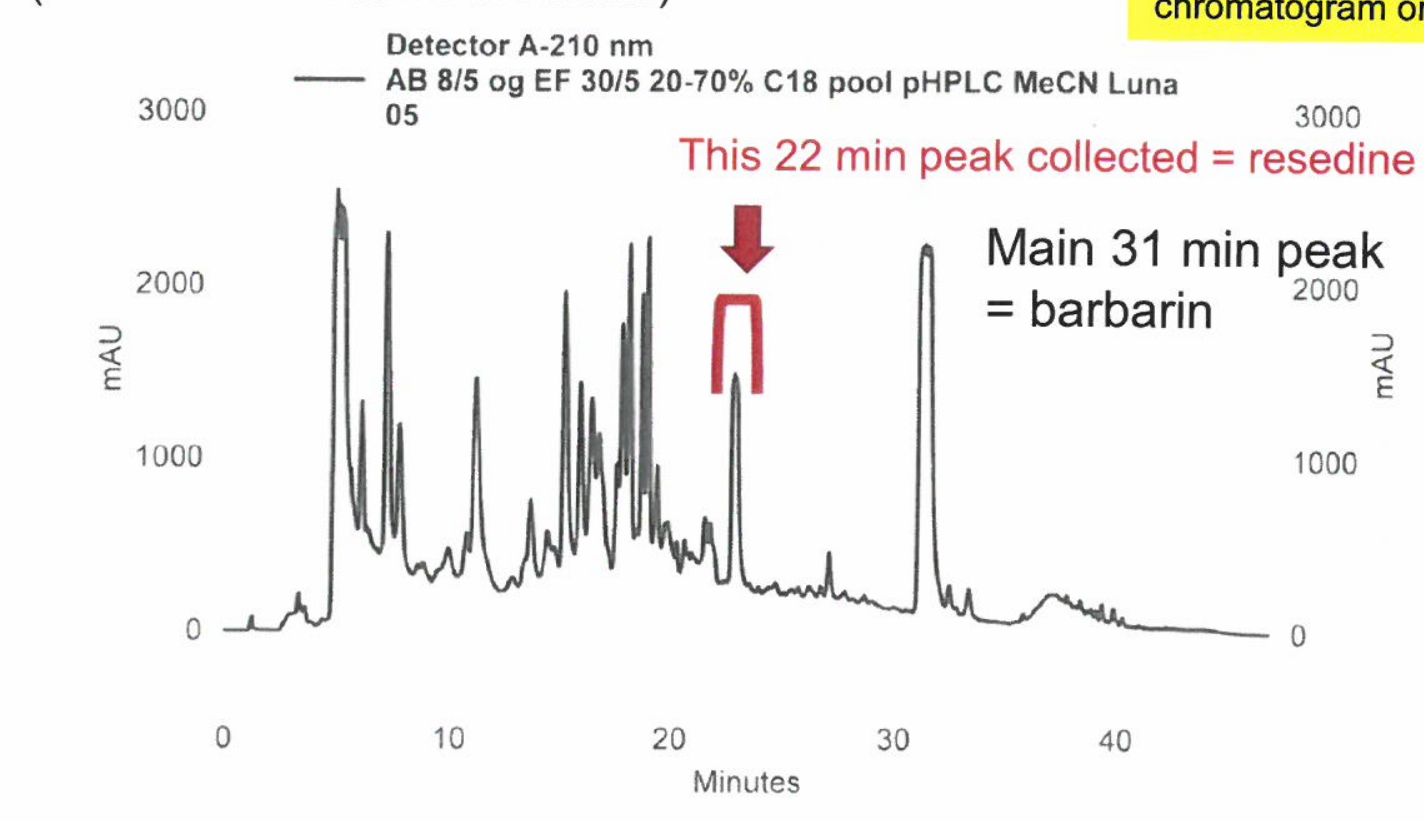

4. Collection guided by real-time chromatogram on screen 
Supplementary Figure 3. ${ }^{1} \mathrm{H}-\mathrm{NMR}$ spectrum $(600 \mathrm{MHz})$ of resedine isolated from autolyzed $B$. vulgaris foliage. Solvent: $\mathrm{CDCl}_{3}$. A. Entire spectrum.

B. Details with chemical shifts in ppm.

C. Details with chemical shifts in Hz. D and E. PERCH analysis of coupling constants.

A

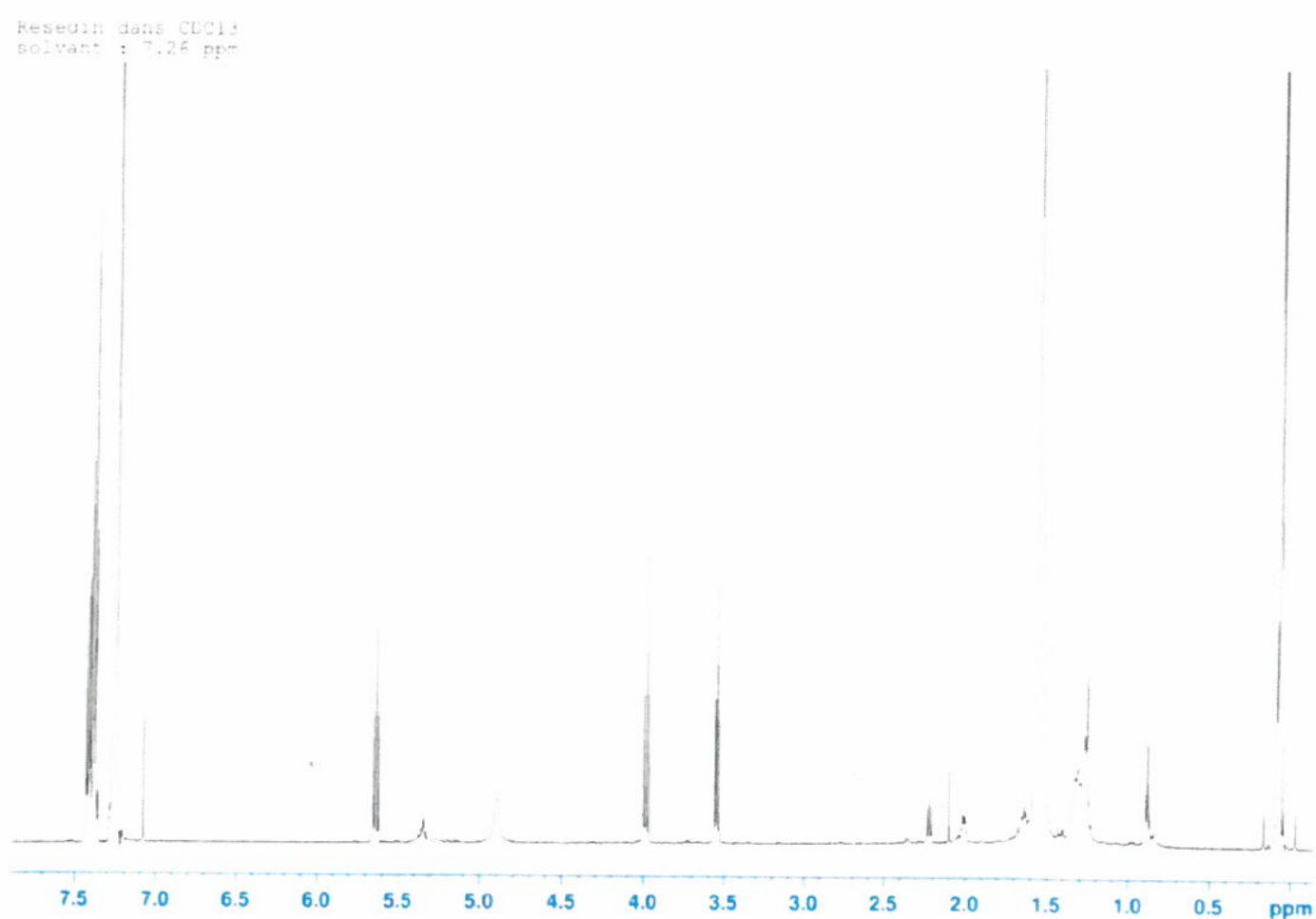

B

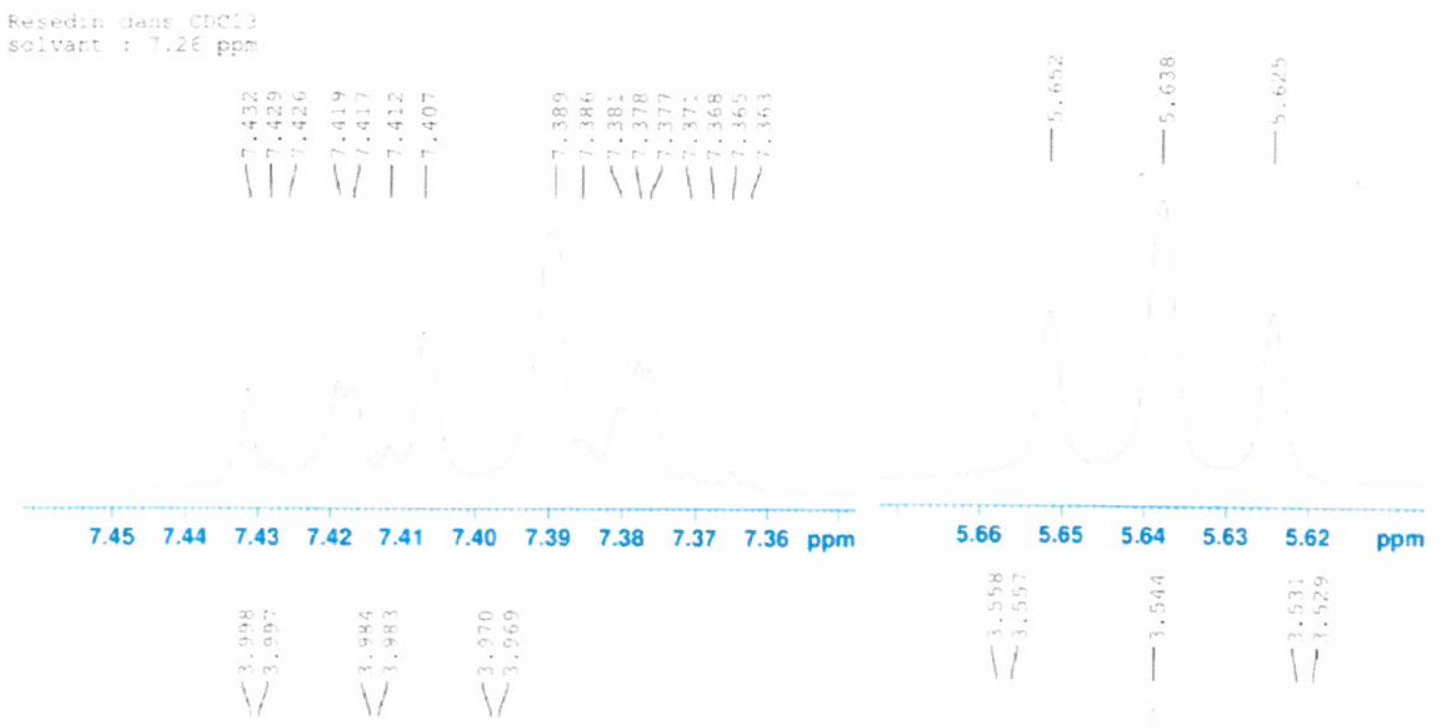




\section{C}
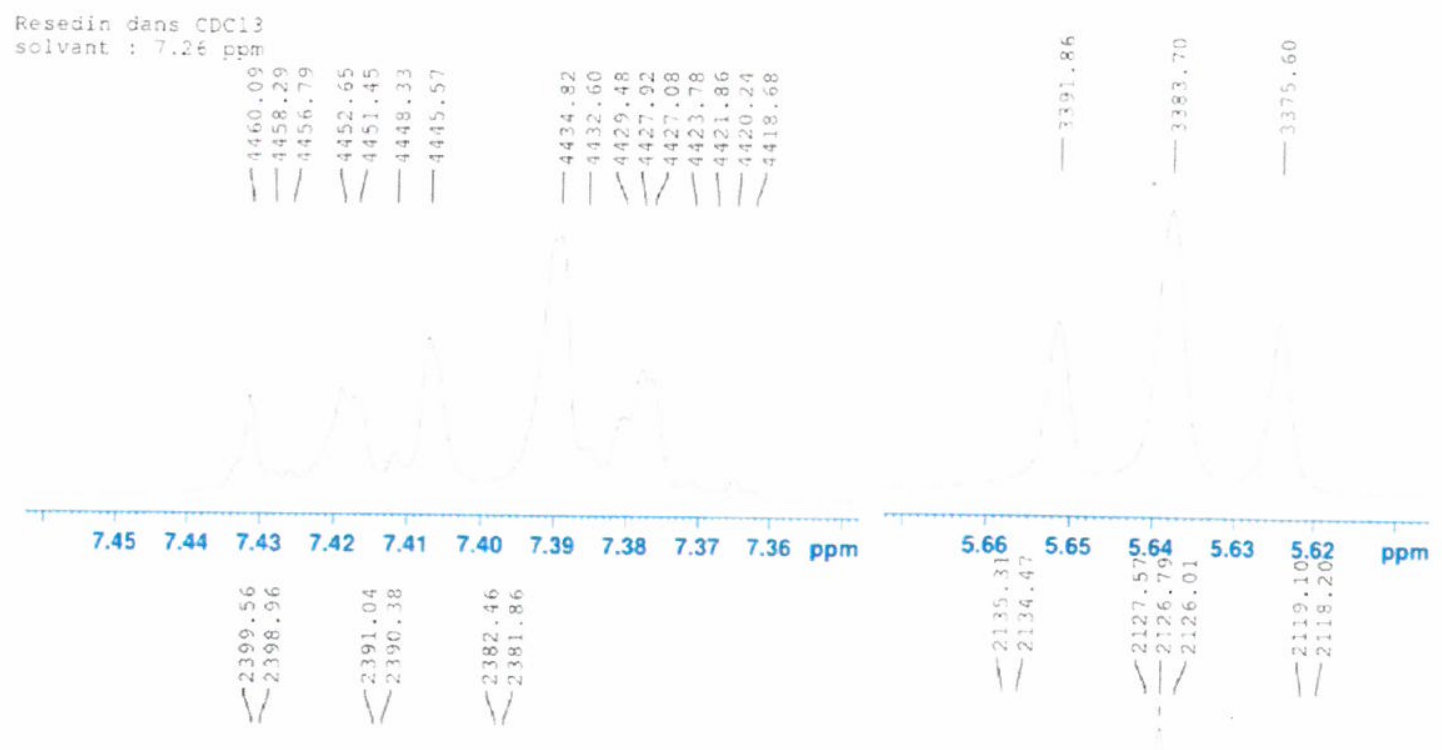

$\begin{array}{llllllll}4.02 & 4.01 & 4.00 & 3.99 & 3.98 & 3.97 & 3.96 & \text { ppm }\end{array}$

3.57

3.56

3.55

3.54

3.53

ppm

D. PERCH Analysis, aromatic part of 5-phenyl-oxazolidine-2-one

Chemical shifts (ppm)

H2/H6: 7.385

H3/H5: 7.417

H4: 7.379

Coupling constants $(\mathrm{Hz})$

H2-H3: 7.83

$\mathrm{H} 2-\mathrm{H} 4: 1.31$

$\mathrm{H} 2-\mathrm{H} 5: 0.52$

$\mathrm{H} 2-\mathrm{H} 6: 2.03$

H3-H4: 7.50

H3-H5: 1.41
E. PERCH Analysis, aliphatic part of 5-phenyl-oxazolidine-2-one

Chemical shifts (ppm)

H3: 4.900

H4a, H4b: 3.544, 3.983

H5: 5.638

Coupling constants $(\mathrm{Hz})$

H3-H4a: 0.94

H3-H4b: 0.75

H4a-H4b: -8.53

H4a-H5: 7.70

H4b-H5: 8.57 


\section{Supplementary Figure 4. Resedine as an autolysis product in watercress, Nasturtium}

officinale. Data files (Agerbirk et al., 2014) from previously published analyses of watercress autolysis and control extracts were searched for signs of resedine (3) in addition to published barbarin (2). The data files were from ion trap HPLC-MS analyses using the same equipment as in the present paper, but not using the optimized detection settings, resulting in much less sensitive detection of low MR metabolites, lack of collection of MS2 spectra, and generally more crowded chromatograms. Likewise, retention times were not exactly those in the rest of the paper due to different conditions in the old experiments. Representative chromatograms show extracted ion chromatograms of an autolysis with added water, giving high yields of barbarin $(A)$, an autolysis without added water, giving lower yields of barbarin for reasons not explained back then (B), and a control boiled extract without autolysis. MS of $\mathbf{2}$ and $\mathbf{3}$ is shown in panel D (next page). The nitrile $\mathbf{4}$ was searched for but not detected (results not shown).

A

Autolysis (3h) with added water

B

Autolysis (3h) without added water

\section{C \\ Direct extraction without previous autolysis}
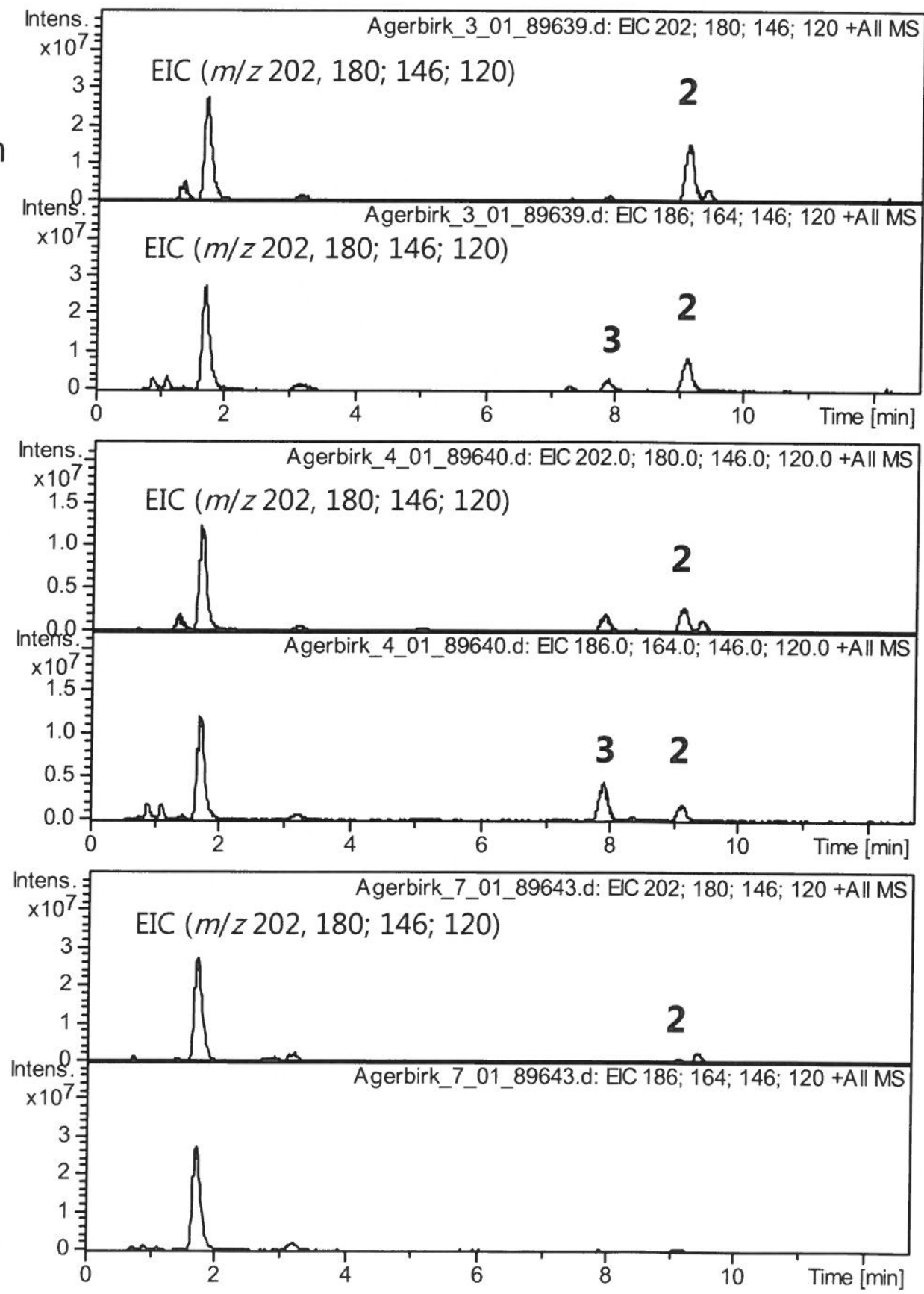
Supplementary Figure 4 (continued). D. Mass spectra of barbarin (2) and apparent resedine (3) from watercress (Nasturtium officinale). The spectra were extracted from The data files also used for panel B. The four signals atributed to resedine coeluted (insert: extracted ion chromatograms showing co-elution of the four mass signals attributed to resedine. The ions at $\mathrm{m} / \mathrm{z} 188$ and 210 were interpreted as signals of a co-migrating metabolite with slightly sharper peak shape.

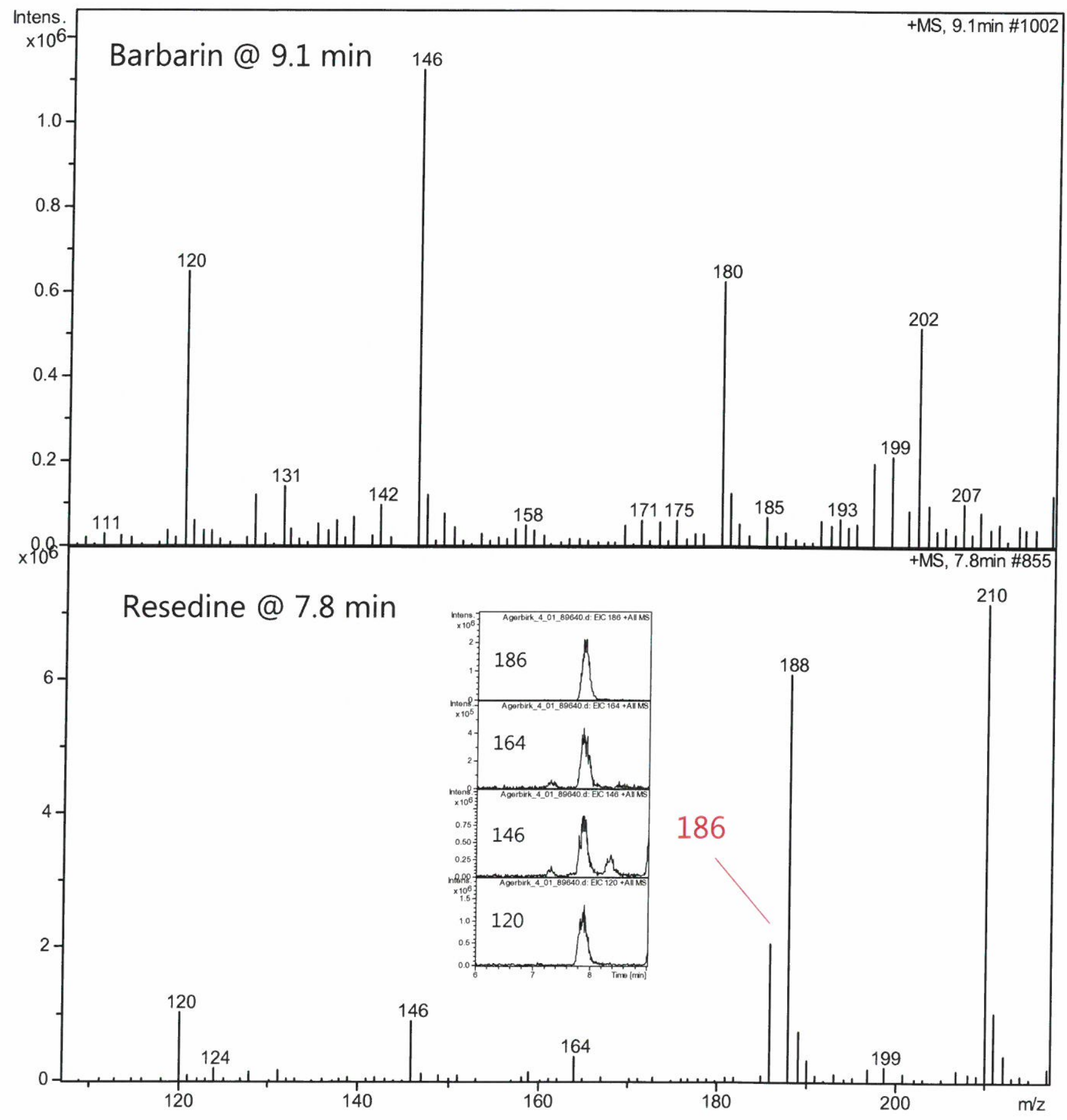


Supplementary Figure 5. Ion trap HPLC-MS (and UV) analysis of extracts of $B$. vulgaris homogenates spiked with either 5-vinylOAT (11) (A) or water (control) (B), showing a tiny peak of the 5-vinyIOAO (12) product. The $t_{R}$ matched the authentic reference, (Supplementary Figure 9$)$ as did the two observed ions $(\mathrm{m} / \mathrm{z} 114$ and 136) in the MS. In a control of 11 incubated in buffer in parallel (c), the peak of 12 was negligible.
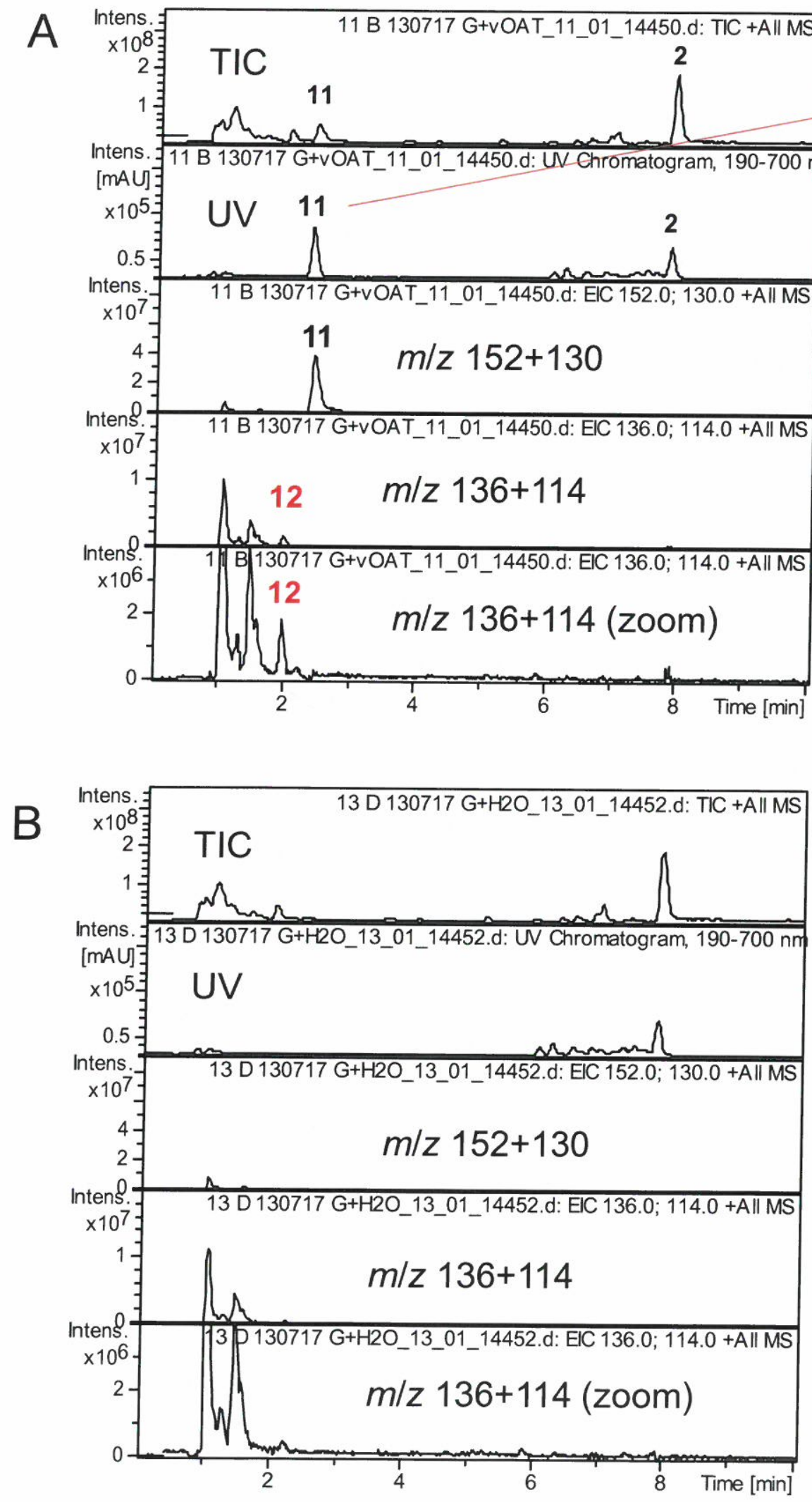

Spiked substrate

MS at 12 peak apex

(Expected: 136 and 114)

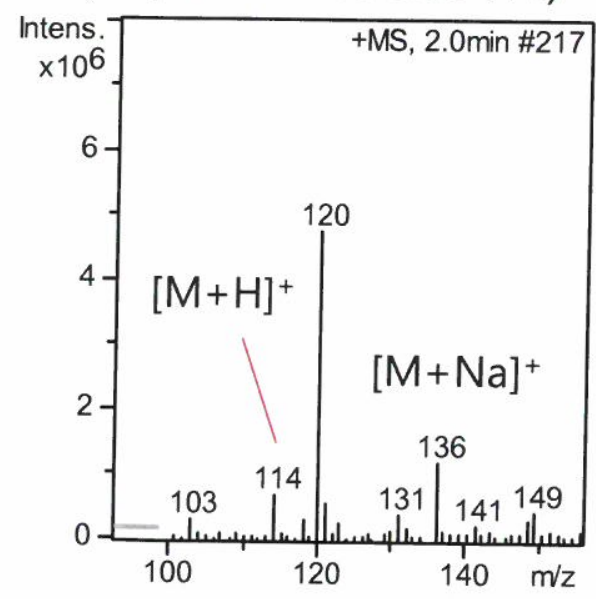

MS at $t_{R}$ corresponding to 12 peak apex

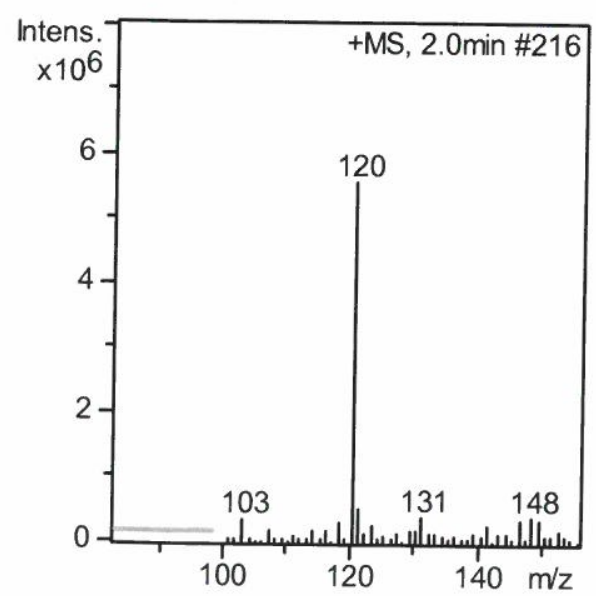


Supplementary Figure 5 (continued from previous page).

C

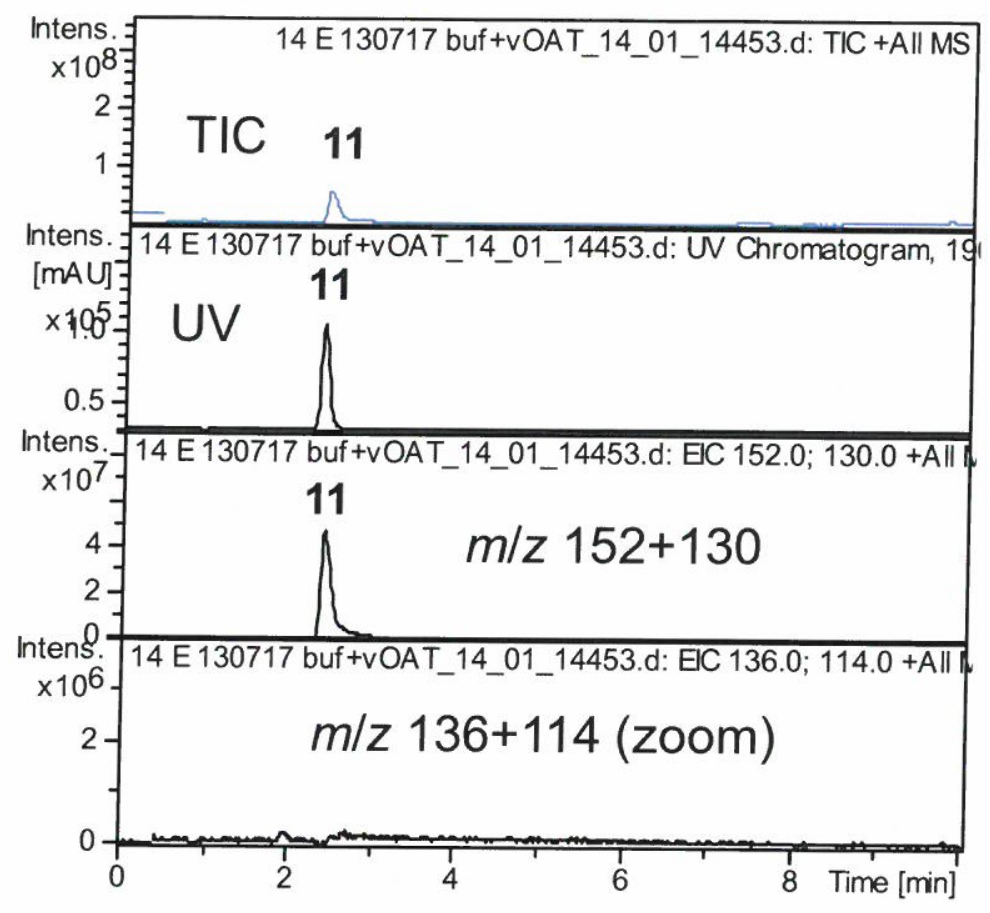




\section{Supplementary Figure 6. HPLC-UV chromatograms of extracts of OAT-spiked}

homogenates as a test for relative concentrations of exogenous OATs and barbarin (2) (at the end of the experiment).

\section{More explanation needed..(Niels)}
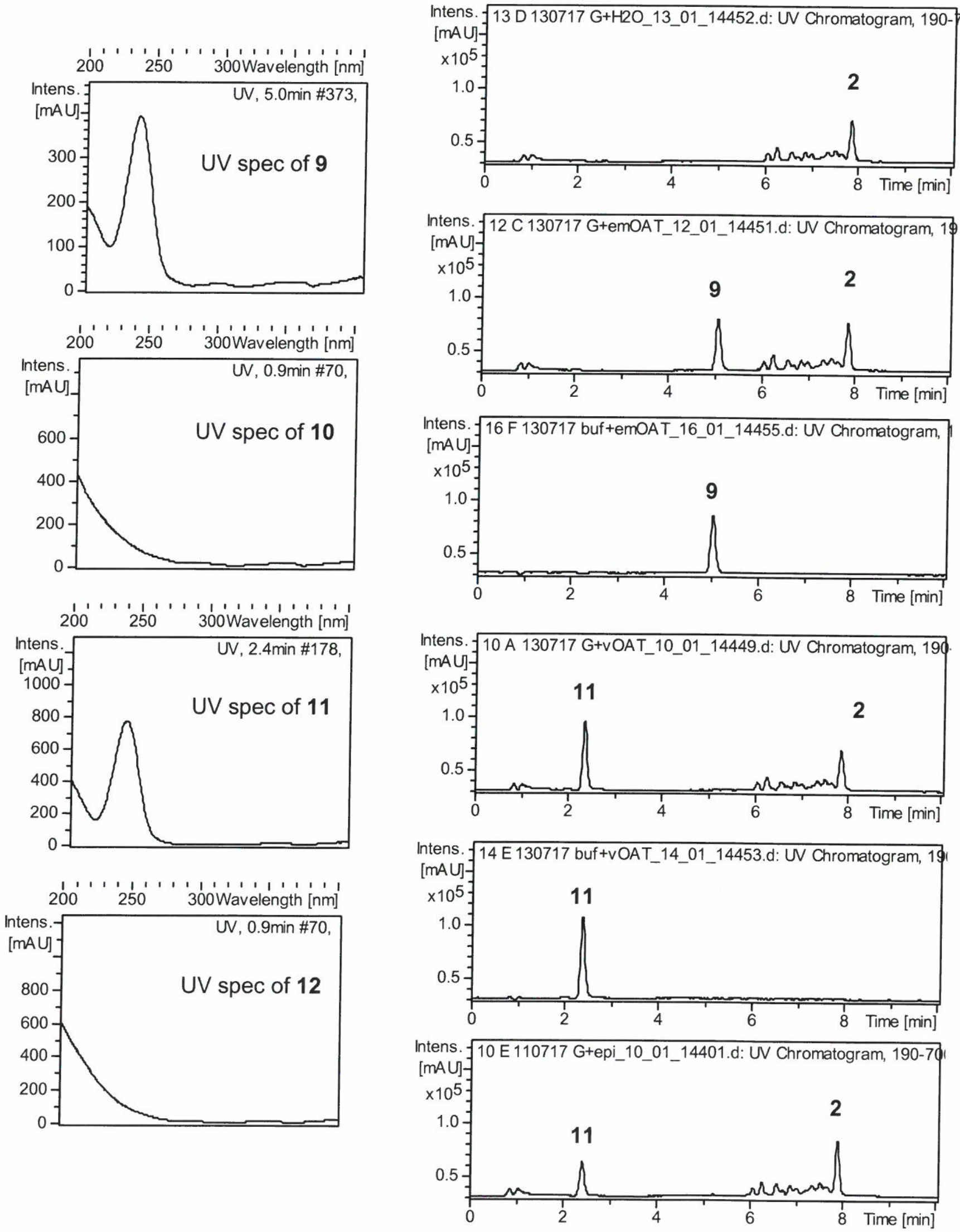


\section{Supplementary Figure 7. Resedine synthesis and MS identification.}

A. Reaction for the synthetic conversion of barbarin (3) to resedine (3) and an amine.

B. Ion trap MS of the product mixture.

Upper lane: TIC. Lower lane, extracted ion chromatogram ( $\mathrm{m} / \mathrm{z} 186$ and 164).

C. Ion trap MS spectra of the amine product.

D. High resolution MS of the amine. product

E High resolution MS of the resedine product.

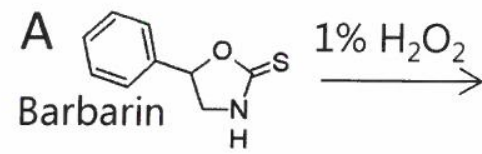<smiles>NCC(O)c1ccccc1</smiles>

B

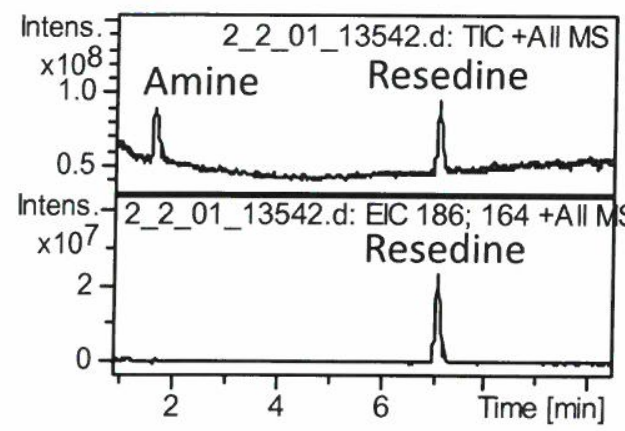

D

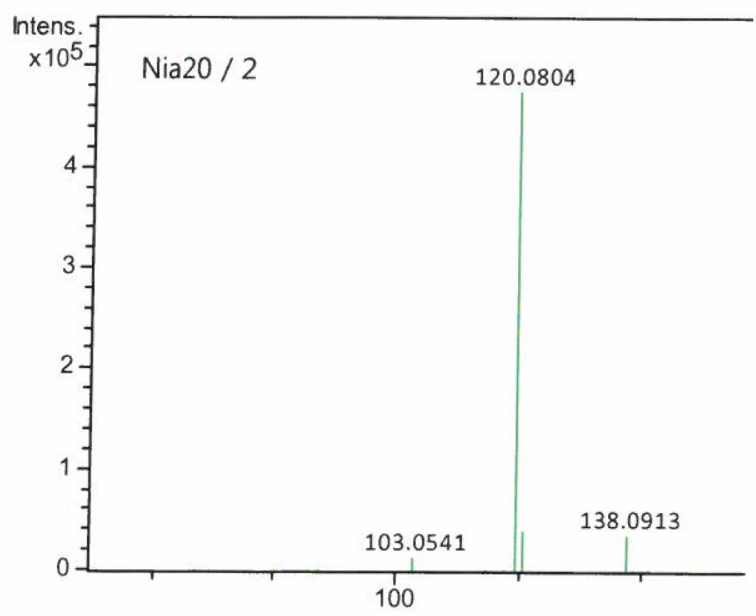

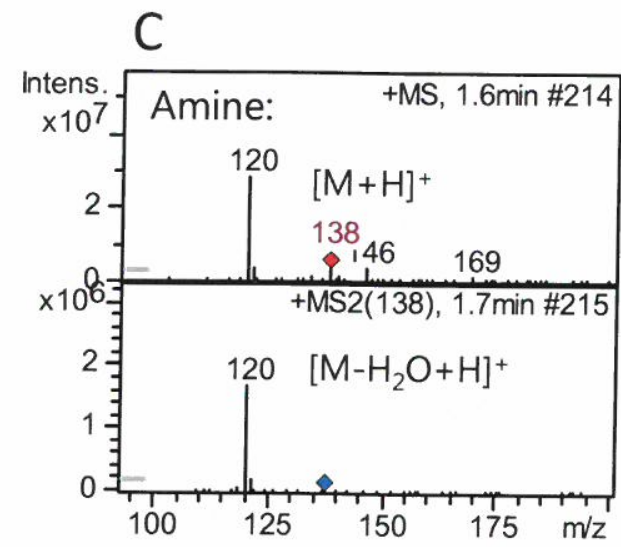

$E$

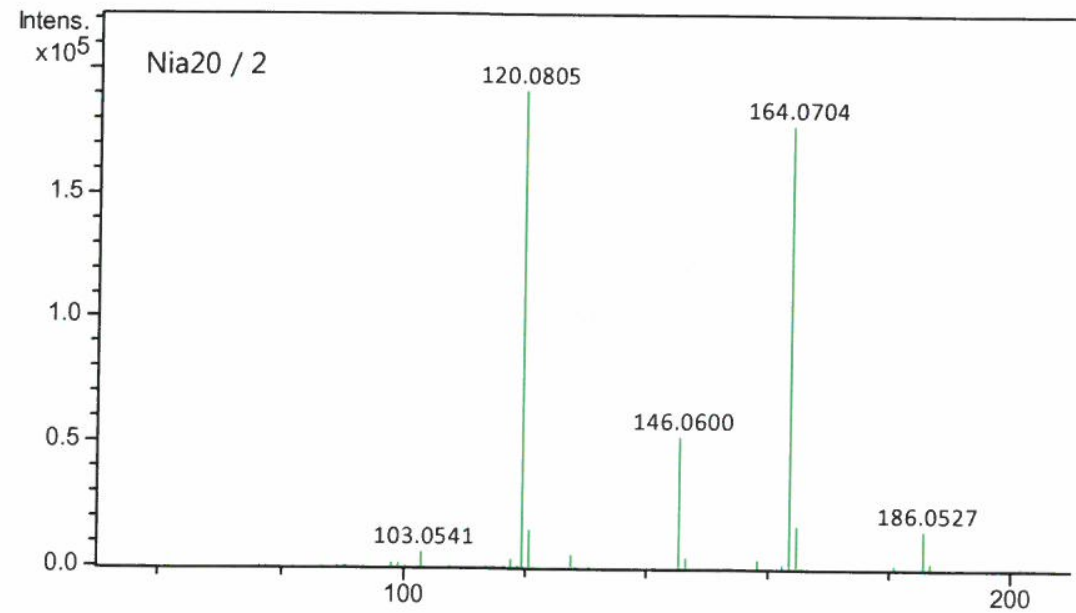

Calc. masses for resedine adducts and fragments:

$[\mathrm{M}+\mathrm{Na}]^{+}: 186.0526$

$[\mathrm{M}+\mathrm{H}]^{+}: 164.0706$

$\left[\mathrm{M}-\mathrm{H}_{2} \mathrm{O}+\mathrm{H}\right]^{+}: 146.0600$

$\left[\mathrm{M}-\mathrm{CO}_{2}+\mathrm{H}\right]^{+}: 120.0808$ 
Supplementary Figure 8: Synthesis of 5-ethyl-5-methylOAO (10) from 5ethyl-5-methylOAT (9)

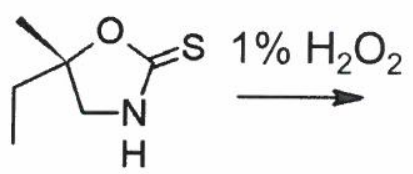

9
Ion trap HPLC-MS/MS

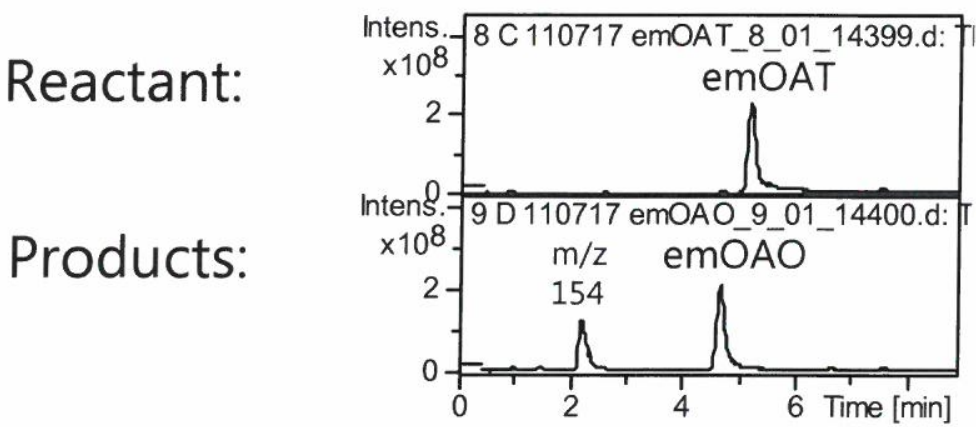

MS of reactant: $\begin{array}{r}\text { Intens. } \\ \times 10^{8}\end{array}$ MS2:

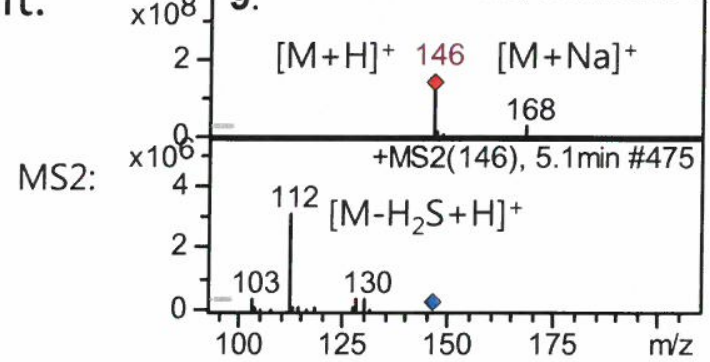

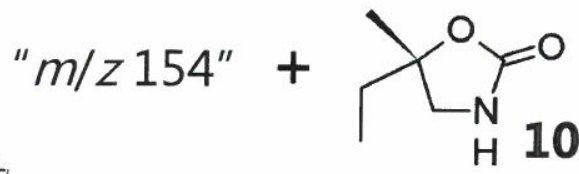

MS of products:

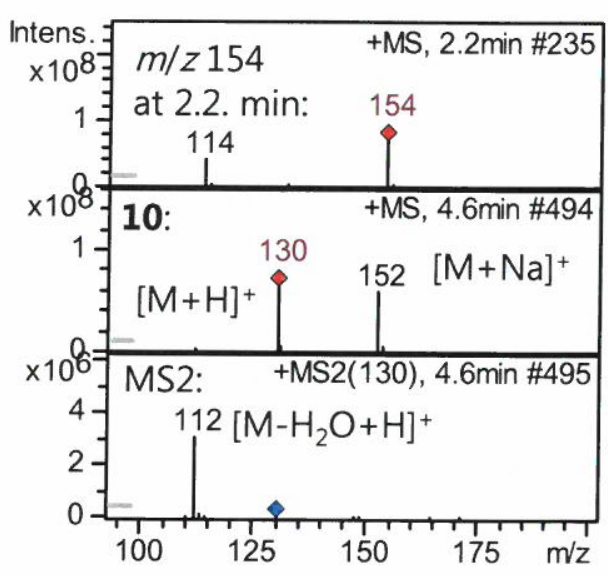

High res. HPLC-MS/MS

9:

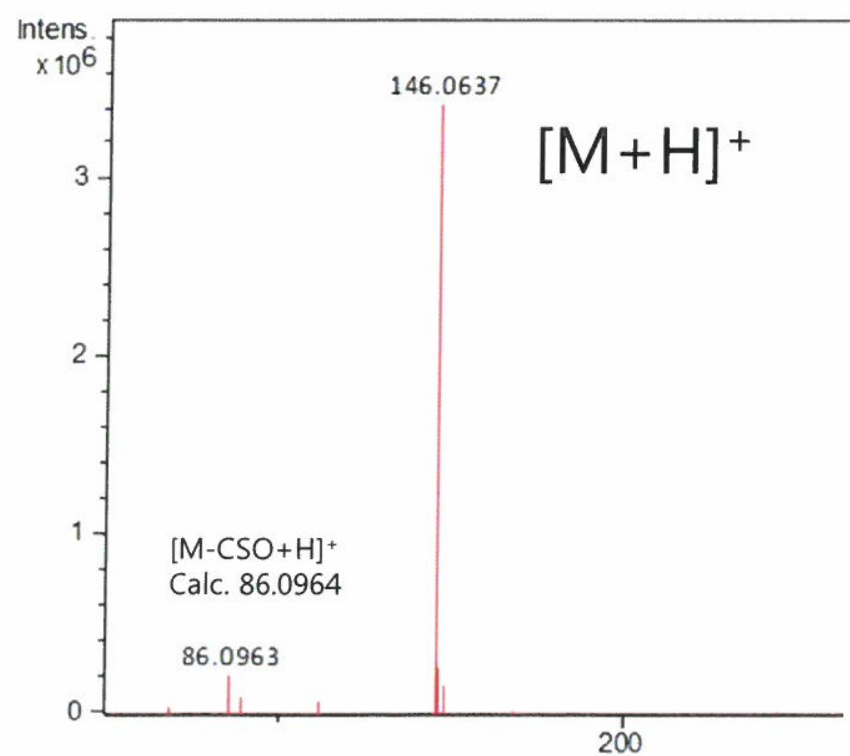

10:

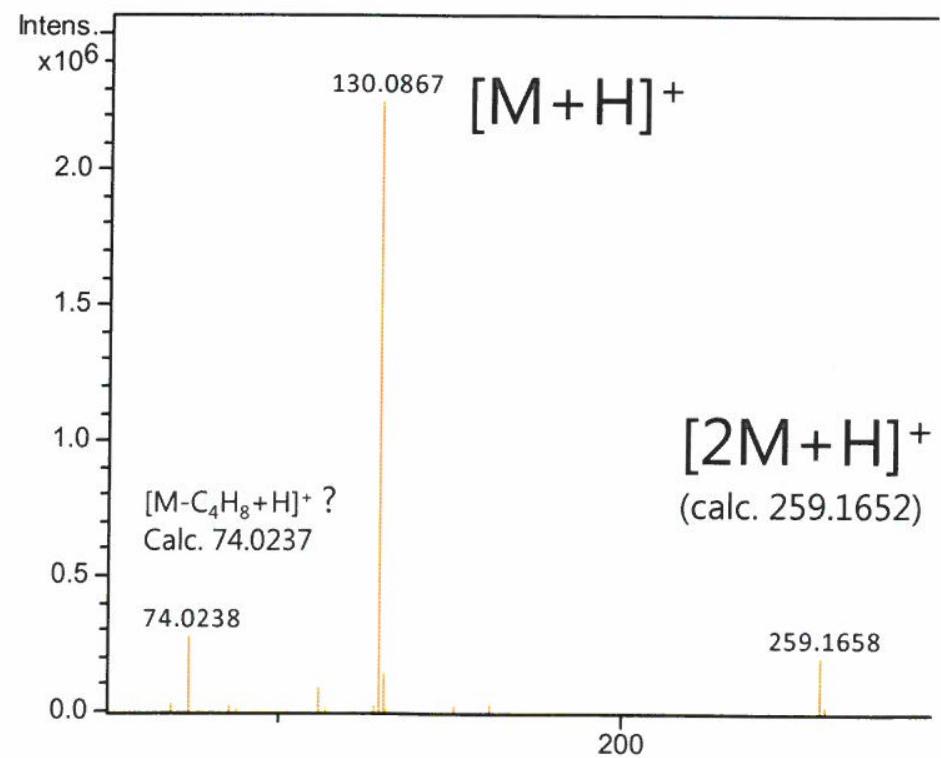




\section{Ion trap HPLC-MS/MS}

\section{Reactant:}
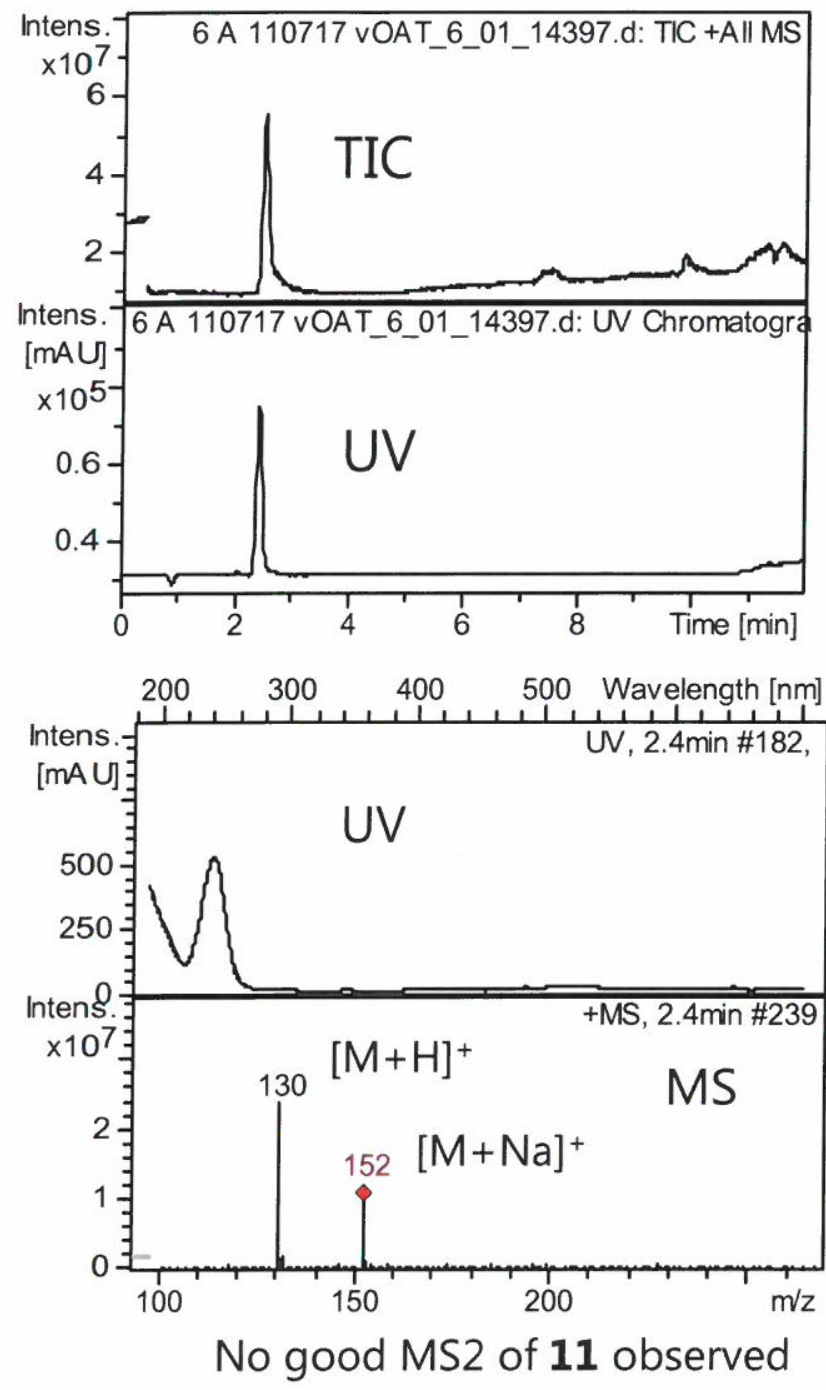

HPLC-QqToF-MS:

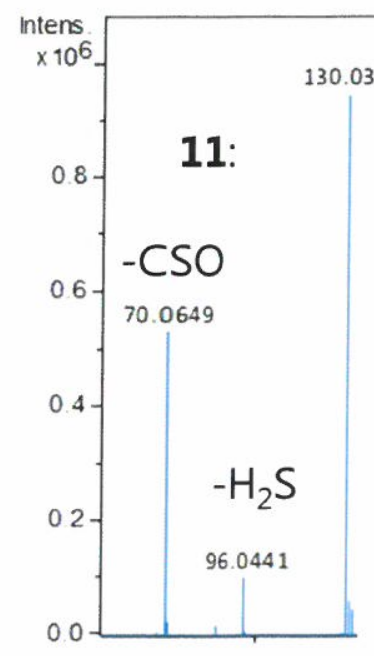

12:

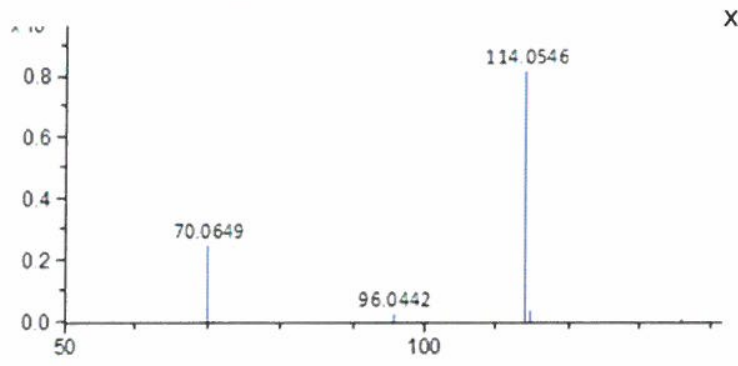

11<smiles>C=CC1CNC(=S)O1</smiles>

\section{Products:}
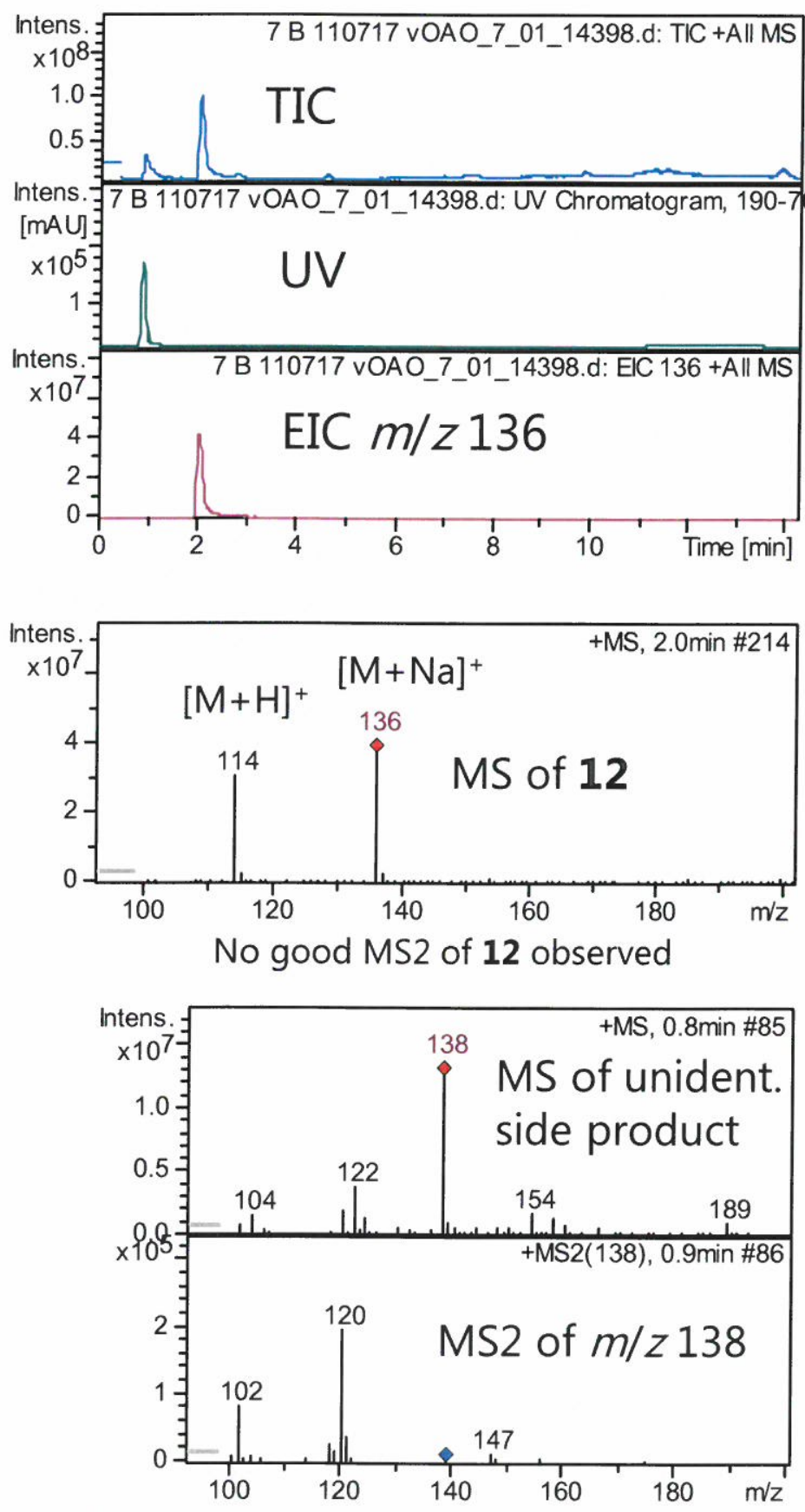